\title{
A Retrospective Chart Review: Nutrition Support in the Neurologically Impaired
}

\section{Child}

\section{A Thesis}

Presented in Partial Fulfillment of the Requirements for the Degree Master of Science in the Graduate School of The Ohio State University

\author{
By \\ Courtney Lynne Strauss \\ Graduate Program in Allied Medical Professions
}

The Ohio State University

2011

Master's Examination Committee:

Marcia Nahikian-Nelms, PhD, RD, LD, CNSC, advisor

Jill Clutter, $\mathrm{PhD}$, MCHES

Lynda Peel, MA, RD, LD 


\section{Copyright by}

\section{Courtney Lynne Strauss}

2011 


\begin{abstract}
The development of a nutrition care plan is a critical component for the clinical care of a hospitalized patient. Enteral feeding is often the sole source of nutrients for patients who are unable to eat. Clinicians must be able to accurately predict the energy needs of the patient to avoid overnutrition or malnutrition which can negatively affect clinical outcomes. Predictive equations have been developed for the estimation of energy needs in adults. For children, the Daily Recommended Intakes (DRIs) are used to estimate energy needs for healthy children. Children who have suffered an event causing neurological devastation have energy needs different than healthy children; however, there is limited data on the metabolism and energy needs of this population. This study sought to retrospectively investigate patterns of energy provision and growth rates in a group of infants admitted to a midwestern children's hospital. Data on 24 patients was collected and analyzed. The growth patterns of these patients fell into one of four groups. Group one was highly variable, group two was predictable, group three was characteristically hypermetabolic, and group four was characteristically hypometabolic. There was no significant majority in any of the groups. This variability illustrates the need for use of more accurate methods of energy needs estimation such as indirect calorimetry. The variability also calls for highly specific and individualized nutrition care plans to be developed for each patient.
\end{abstract}


For my always supportive parents, Richard and Terri.

Thank you for all you have given me. 


\section{Acknowledgments}

I would like to acknowledge and thank my advisor, Dr. Marcia Nahikian-Nelms, for her help, guidance, and support throughout the writing of this thesis. I am greatly appreciative of her time spent and contributions to this paper.

I would also like to thank Dr. Jill Clutter, and Lynda Peel for their time and support. I am greatly thankful for their knowledge and expertise in helping me complete this work. 
Vita

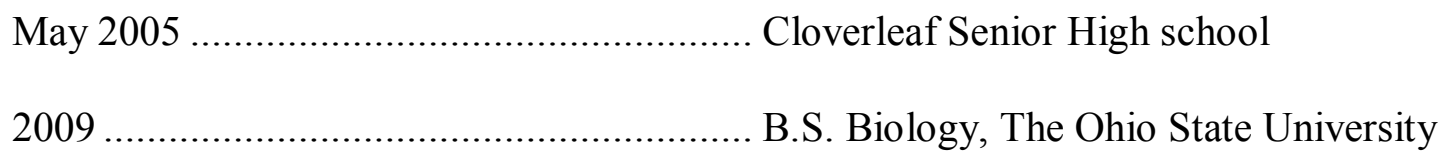

Fields of Study

Major Field: Allied Medical Professions 


\section{Table of Contents}

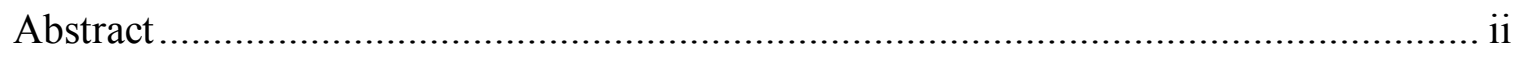

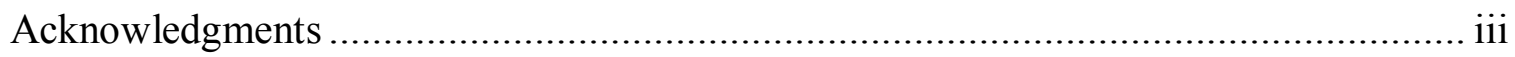

Vita

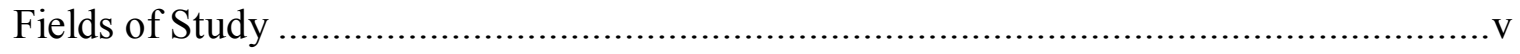

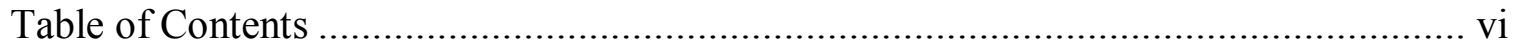

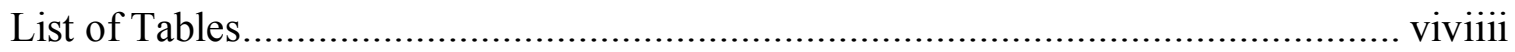

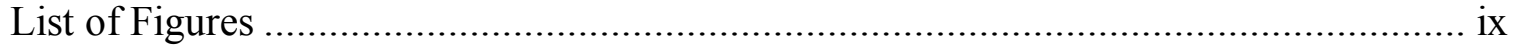

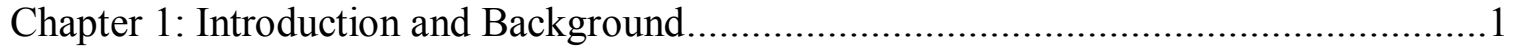

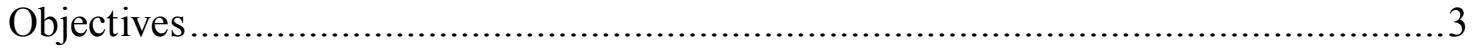

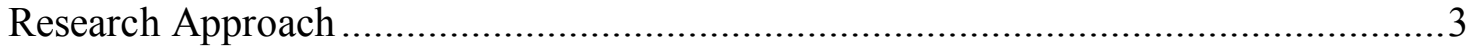

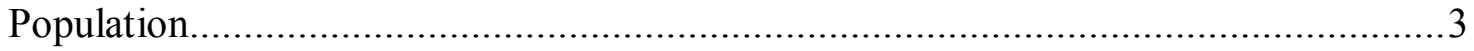

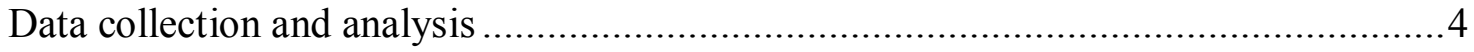

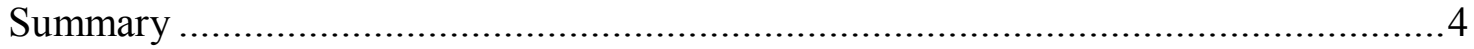

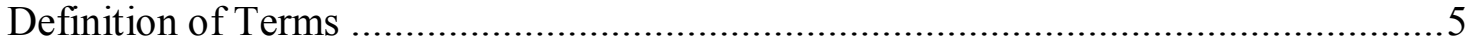

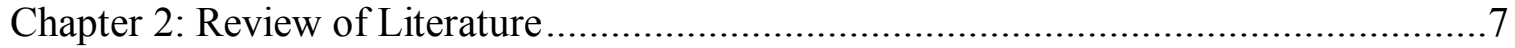

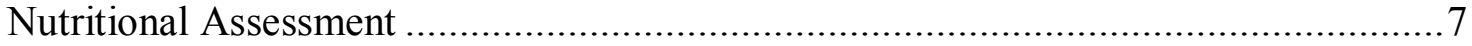

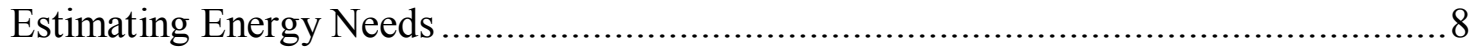

Estimation of Energy needs by Predictive Equations …….......................................

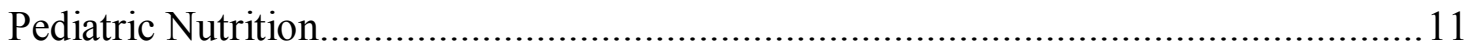

Estimating Energy needs in Healthy Infants and Children ....................................... 13

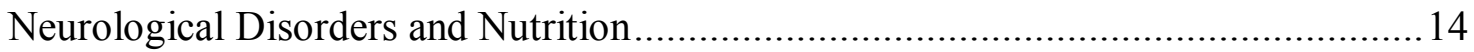

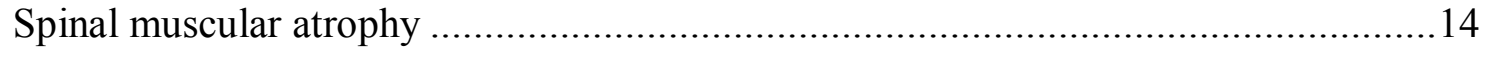

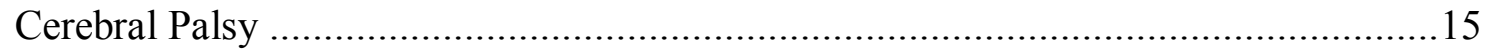

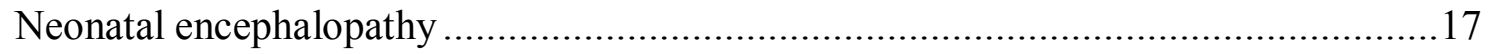

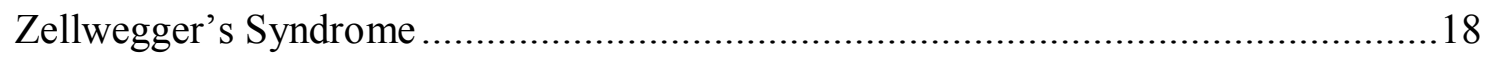




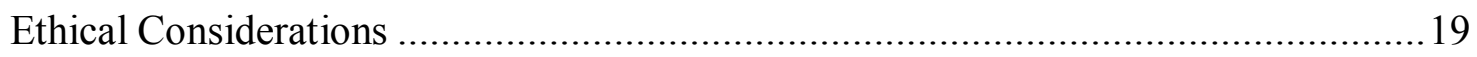

Nutrition Support in the Neurologically Devastated Infant .....................................20

Estimating energy requirements of children with neurological disorders ..................22

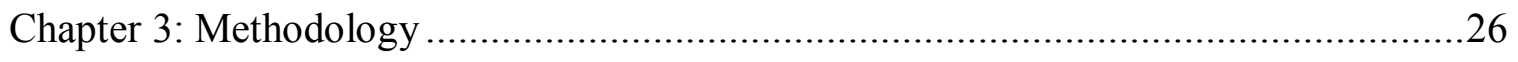

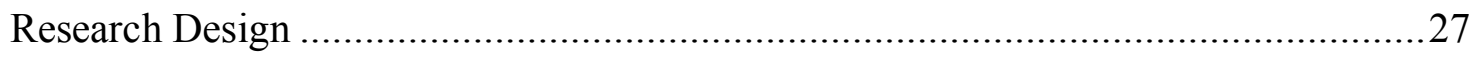

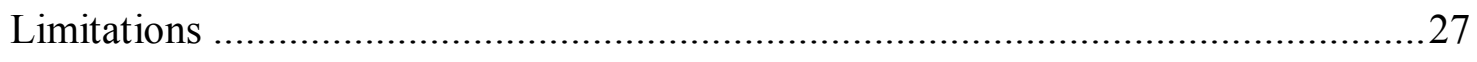

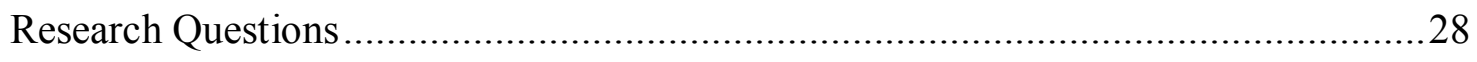

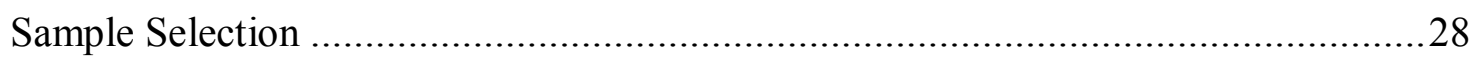

Data Analysis and Instrumentation..............................................................29

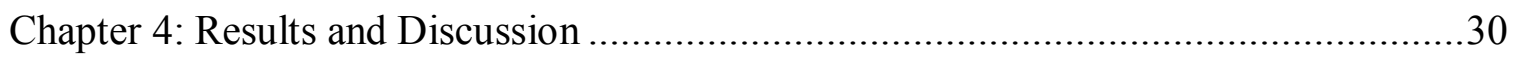

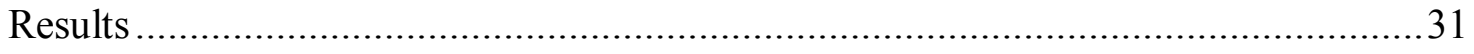

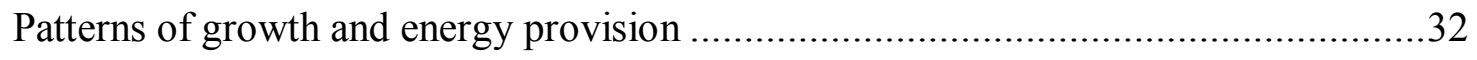

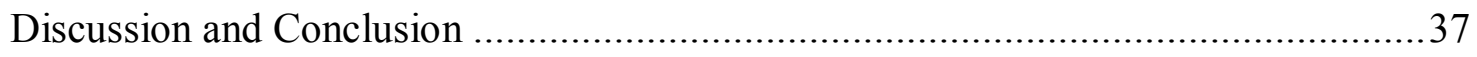

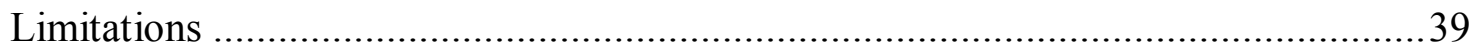

Chapter 5: A Retrospective Chart Review: Nutrition Support in the Neurologically

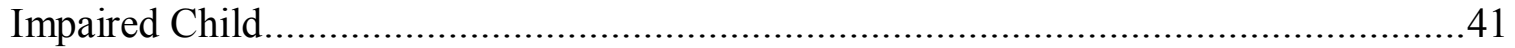

Abstract




\section{List of Tables}

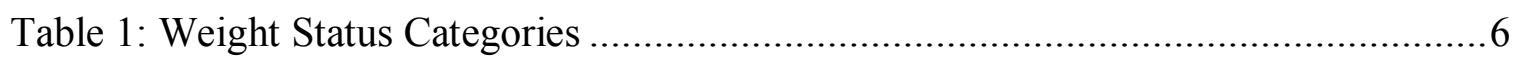

Table 2: Diagnoses included in data analysis ..............................................................

Table 3: Description of subjects at initial assessment ….................................................32

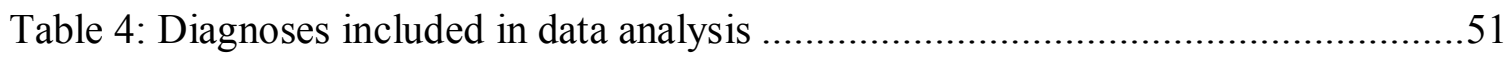

Table 5: Description of subjects at initial assessment ……….......................................32

Table 6: Description of groups and growth patterns exhibited ....................................532 


\section{List of Figures}

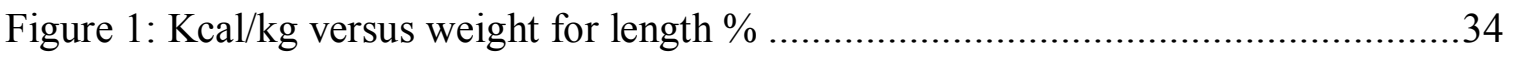

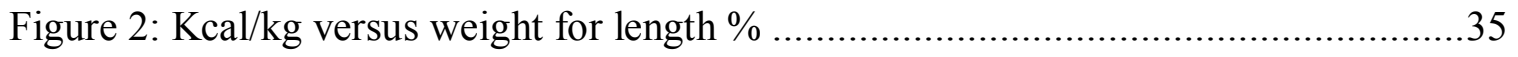

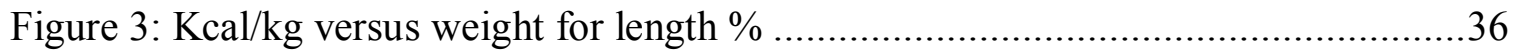

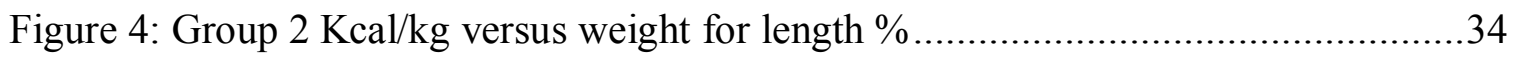

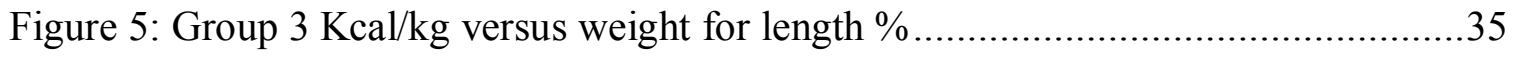

Figure 6: Group $4 \mathrm{Kcal} / \mathrm{kg}$ versus weight for length $\%$...........................................36 


\section{Chapter 1: Introduction and Background}

Maintenance of energy balance is a crucial component of nutritional status. Optimal body function requires macronutrient intake to meet energy requirements. A delicate balance must be achieved as giving the body too many nutrients and energy can lead to obesity and denying the body adequate nutrients and energy can lead to malnutrition.

The energy requirements, which are met by macronutrient intake, are the levels of nutrients needed for normal physiology. Nutrients are broken down and transformed into adenosine triphosphate, ATP, the fuel for the body's cells. Without adequate ATP production, cells are unable to develop properly and perform their specific tasks.

The energy needs of healthy individuals are calculated in various ways. Direct calorimetry measures energy expenditure by calculating the amount of energy, in the form of body heat that is released by a person. The heat is measured by placing the person in an insulated chamber where the released heat can be captured. Indirect calorimetry estimates energy expenditure by measuring the inspired oxygen and expired carbon dioxide from an individual. Carbon dioxide is a by-product of metabolism and the oxygen consumption and carbon dioxide expiration can be analyzed to estimate the amount of energy used by the body. Historically, because both methods can be timely and costly, predictive equations have been developed to be used as alternative tools to 
estimate energy needs in humans ${ }^{1}$. These equations use factors such as age, height, weight, and activity to estimate the total amount of energy one would need to maintain their energy balance. These equations can also be used for individuals with circumstances that may affect their energy needs. These include, but are not limited to, burn victims, cancer patients, amputees, post-surgical patients, and those in need of weight loss or gain. Using these predictive tools in the clinical setting helps in determining the appropriate nutrient intake for a person that will not lead to either malnutrition or overfeeding, both of which can cause complications.

Energy expenditure in a person is drastically affected by the amount of work performed by the muscles in the body. Brain function, especially during the formative years, also contributes to the energy needs of individual ${ }^{2}$. Children that have little or no function in their muscles or brain require an altered amount of energy compared to children born to term without any health complications. These include but are not limited to, those diagnosed with spinal muscular atrophy, cerebral palsy, neonatal encephalopathy, and any other conditions of neurologic or neuromuscular devastation. The clinical assumption would be that these individuals would require an altered amount of energy due to lack of movement. However, at this time there are limited predictive methods of estimating energy needs for these types of individuals. Physicians and dietitians are calculating energy needs primarily by extrapolation from a clinical practice precedent of similar pediatric diagnoses.

It is crucial to evaluate the current level of care for neurologically devastated infants and children so that the appropriate levels of energy intake of these individuals can be determined. Without any reference as to what they need, they are at a greater 
nutritional risk of both under nutrition and over nutrition. Under nutrition affects the body's processes of healing, growth, and immune function. Over nutrition can lead to excessive weight gain that may lead to metabolic complications which can adversely affect daily care.

\section{Objectives}

The purpose of this study was to gain a better understanding of the typical nutritional care of neurologically devastated, immobile, enterally fed infants and children. By examining nutritional and medical history of individuals with neurologic disorders, the researcher aimed to find trends and patterns which would help define energy calculations. This study focused on children affected by neurologic disorders and their medical and nutritional history. Quantitative and qualitative analysis of information from past medical records were the basis of this descriptive study.

\section{Research Approach}

The following information was gathered from medical records, as available, to document nutritional care and growth trends: diagnoses, height, weight, weight/height, and nutrition prescriptions. This information was gathered from the patient's medical record and from the nutrition progress notes by a Registered Dietitian. Once identified, this information was organized and analyzed qualitatively to assess and recognize patterns that may contribute to the understanding of the altered energy needs of children affected by neurologic disorders.

\section{Population}

This study included patients admitted to Nationwide Children's Hospital, Columbus, Ohio, from 2006 to June 2011. It included patients with the diagnoses related 
to neurological devastation. Nationwide Children's Hospital is a comprehensive pediatric hospital and research institute that serves approximately 933,000 patients annually from all areas of the world ${ }^{3}$. Of these patients, almost 12,000 patients are treated by the neurology specialty clinic, making neurology the seventh highest volume specialty area. Because this hospital treats a wide variety of individuals, the results of this study may reflect a larger population regardless of the small sample.

Data collection and analysis

Data identified from the medical record was collected on study specific case report forms. The data collected was directly from hospital admissions and was a component of the permanent medical record. The data was then analyzed using a variety of descriptive statistics and a qualitative discussion of the results is presented. This study was approved by the Institutional Review Board at Nationwide Children's Hospital.

\section{Summary}

Energy balance describes the clinical situation that allows for adequate energy to meet nutritional needs and growth without contributing to excessive fat deposition. It is necessary to be able to estimate the energy needs of individuals in order to avoid complications that accompany malnutrition or over nutrition. Predictive energy equations are an important component of clinical practice when determining the nutrition therapy prescription for the patient. In the clinical situation where the patient is immobile, the clinical care must rely on nonspecific estimations. These individuals are at higher risk for malnutrition as well as overnutrition. Nutrition recommendations for the pediatric population are based on predictive tools for healthy individuals and are therefore not appropriate given this population's immobility and presumed altered energy requirement. 
By investigating trends and patterns of nutritional and medical information, this study aimed to further the understanding of altered energy needs in neurologically devastated individuals.

\section{Definition of Terms}

1. Malnutrition- faulty nutrition due to inadequate or unbalanced intake of nutrients or their impaired assimilation or utilization.

2. Indirect calorimetry- any of several apparatuses for measuring quantities of absorbed or evolved heat, or for determining specific heats used to determine calorie consumption at rest.

3. Spinal muscular atrophy - any of several inherited disorders (as KugelbergWelander disease) that are characterized by the degeneration of motor neurons in the spinal cord resulting in muscular weakness and atrophy and that in some forms (as Werdnig-Hoffmann disease) are fatal

4. Cerebral palsy - a disability resulting from damage to the brain before, during, or shortly after birth and outwardly manifested by muscular un-coordination and speech disturbances

5. Hypoxic ischemic encephalopathy - Damage to cells in the central nervous system (the brain and spinal cord) from inadequate oxygen. Hypoxic-ischemic encephalopathy allegedly may cause in death in the newborn period or result in what is later recognized as developmental delay, mental retardation, or cerebral palsy. (http://www.medterms.com/script/main/art.asp?articlekey=3875) 
6. BMI- body mass index, a measure of body fat that is the ratio of the weight of the body in kilograms to the square of its height in meters. In children, BMI is determined using a BMI-for-age percentile status. See table below. (http://www.cdc.gov/)

\section{Weight Status Category}

Underweight

Healthy weight

Overweight

Obese

\section{Percentile Range}

Less than the $5^{\text {th }}$ percentile

$5^{\text {th }}$ percentile to less than the $85^{\text {th }}$ percentile

$85^{\text {th }}$ percentile to less than $95^{\text {th }}$ percentile

Table 1: Weight Status Categories

(Unless noted, all definitions are from Medline Plus, online dictionary.

http://www.nlm.nih.gov/medlineplus/mplusdictionary.html) 


\title{
Chapter 2: Review of Literature
}

\author{
Nutritional Assessment
}

Proper nutrition, providing adequate nutrients, is important for optimal physiological function. Consuming adequate amounts of necessary nutrients has not always been as easy as it is today. Deficiency diseases including rickets, scurvy, pellagra and beriberi were common during the nineteenth century and first half of the twentieth century. Advancements in food supply such as nutrient fortification and enrichment have helped to decrease nutrient-deficiency diseases to an almost non-existent level ${ }^{4}$.

Although nutrient-deficiency diseases are more infrequent, nutrition related diseases continue to be a pressing issue in today's society. Identifying individuals who are at risk for nutrition related diseases is essential. By identifying those at risk, the negative effects and progression of the disease itself can, at times, be avoided completely. There are certain characteristics that can be identified as nutrition related to determine disease risk factors. Some of these characteristics are BMI values, body composition measurements, abnormal blood values and food intake. Nutrition screenings and assessments provide the steps to identify these risk factors ${ }^{4}$.

Nutrition screening and assessment of hospitalized patients is a required component of health care. By evaluating the nutritional status of medically fragile pediatric patients, clinicians can identify patients who are at high risk and more 
efficiently plan appropriate interventions ${ }^{5}$. It has been found that those who are at nutritional risk upon admission and throughout their stay in the hospital are associated with prolonged hospital stays ${ }^{6}$. Malnutrition and its effect on the length of hospital stay is an important factor that clinicians need to be aware of ${ }^{5}$.

Weight measurements, weight history, height, BMI, and adequacy of food intake are data that are collected upon admission to evaluate patients' nutritional status ${ }^{6}$. In children, growth charts are another tool which is utilized in assessing the nutritional status. While most of the measurements taken are of a straightforward nature, adequacy of intake is not. Food intake can be recorded in various ways including a 3-day diet record or general diet histories. In order to assess the appropriateness of the patients' dietary intake, data must be compared to standard requirements of energy needs.

\section{Estimating Energy Needs}

By estimating energy needs of patients, appropriate intake can be established which helps to avoid malnutrition and over nutrition, both of which can cause medical complications. In the clinical setting, malnutrition is associated with increased infection risk, decreased healing rates and altered cell function ${ }^{7}$. Because of these risks, proper nutritional assessment is of great importance to the general population, and even more so in hospitalized patients.

Measuring a patient's resting energy expenditure is the best way to accurately assess the energy needs of the patient. Resting energy expenditure (REE) is the energy necessary to sustain life and to keep vital organs such as the heart, lungs, brain, liver, and kidneys functioning ${ }^{8}$. By measuring the REE of a patient, the clinician then has a base value to build an appropriate nutrition prescription. REE is obtained after a patient has 
been resting quietly for 30 minutes prior to the test ${ }^{8}$. REE can be measured by direct calorimetry or indirect calorimetry. Direct calorimetry involves a sealed chamber where the amount of heat given off by the body can be measured. This amount of heat can be used to provide a highly accurate measurement of REE. Although the measurements using direct calorimetry are precise, the expense and inconvenience of this method limit its use ${ }^{4}$. Indirect calorimetry involves the collection of expired air, and the analysis of oxygen and carbon dioxide concentrations to determine $\mathrm{REE}^{4}$. Although direct and indirect calorimetry are the gold standards in measuring REE, their use is limited in the hospital setting as they are much more labor intensive, invasive, and also require a narrow range of clinical conditions ${ }^{9}$. The cost and inconvenience of the process make it impossible to perform on every patient.

\section{Estimation of Energy needs by Predictive Equations}

In most hospital settings energy needs are estimated using established equations based upon a number of characteristics of the patient. There are numerous equations that have been developed; each one having a specific target population. Used most conventionally, the Harris Benedict was developed in 1919 by determining the resting energy expenditure of 239 healthy young adults using indirect calorimetry. Using the data gathered, a regression equation was derived to estimate energy needs using the variables: weight, stature, age, and $\operatorname{sex}^{4}$. The Mifflin St. Jeor equation was developed in much the same way, using a sample of 498 normal-weight, obese, and severely obese individuals ${ }^{10}$. Validation studies of the equations have found the Harris Benedict equation to accurately predict energy requirements of $45-80 \%$ of individuals. Validation studies have shown the Mifflin St. Jeor to be able to accurately predict energy needs of individuals within $10 \%{ }^{10}$. 
Since these equations were developed with the use of healthy individuals, and not using medically fragile subjects, the American Dietetic Association evidence analysis library strongly suggests that these equations may give inaccurate estimations in critically ill populations ${ }^{11}$.

In the hospital setting, there are various other equations which are deemed more appropriate for a critically ill population. First, the Swinamer equation, published in 1990, was based on observations in 112 mechanically ventilated, critically ill trauma, surgical, and medical patients before nutrition support was initiated ${ }^{12}$. This equation uses variables including body surface area, body temperature, respiratory rate and tidal volume of the patient. Validation of this equation's use in medically fragile populations is limited; however, because there is no other evidence against the equation it continues to be used ${ }^{11}$.

Secondly, the Ireton-Jones was developed from 65 critically ill adults and their resting metabolic rate measurements. It includes variables of weight, age, sex, level of trauma, and whether or not the patient was a burn victim. Although this equation has more validation studies, the accuracy rates are not sufficient for clinical confidence. However, as with the Swinamer equation, because no other evidence exists arguing against the equation, it continues to be used ${ }^{11}$.

The third equation deemed appropriate for use in a critically ill population is the Penn State Equation. This equation is derived from data collected over 6 years on 169 mechanically ventilated patients consisting of a mix of trauma, surgery and medicine patients. The equation actually incorporates the Harris-Benedict equation with other variables including maximum body temperature over the previous 24 hours, body weight, 
and minute ventilation in $\mathrm{L} / \mathrm{min}$. This equation had the highest accuracy rate and the lowest rate of large errors of any validated equations which led to the conclusion that it may be used in critically ill populations ${ }^{11}$.

Although these equations are approved for the use in critically ill populations, more validation studies are necessary to further assess the true accuracy of their predictions $^{11}$.

\section{Pediatric Nutrition}

Proper nutrition is most critical during infancy and childhood. During infancy, the energy needs per kg are higher than any other time in life. The increased energy requirements are due to the development of many body systems throughout the formative years as organs continue to grow and motor development begins ${ }^{13}$. The amount of calories is increased after motor development due to the energy expended with muscle movement. It is crucial for infants and children to receive adequate nutrients. Agostoni et al. stated that nutrient requirements per kg body weight are significantly higher in growing children than in adults, making the children much more vulnerable to the effects of malnutrition ${ }^{14}$.

Nutrition screening, assessment and the development of an individualized care plan should be a requirement for critically ill children upon admission to the hospital, as stated by A.S.P.E.N. guidelines on Nutrition support of the critically ill child. Tume et al. found that even relatively short periods of malnutrition in infancy may have effects on neurological and cognitive development ${ }^{15}$. As with adults, weight measurements, length, BMI and other anthropometric measurements of children are taken. Measurement of nitrogen balance, and prealbumin are among other indices collected during a nutritional 
assessment ${ }^{16}$. These indices assist clinicians in understanding the nutritional status of admitted pediatric patients and help to avoid malnutrition and its consequences.

Another set of tools used in the nutritional assessment of children are growth charts. A child's weight, height, BMI, or head circumference can be plotted onto these growth charts and the percentile of growth can be analyzed. This analysis compares growth to other children of the same age and is a fundamental screening tools for nutritional assessment in children ${ }^{4}$. The charts were developed by the U.S Centers for Disease Control and based on measurements from nationally represented, apparently healthy, well nourished samples of infants, children, and adolescents during a series of health examination surveys ${ }^{4}$. There are two sets of charts, one for birth to 36 months of age, and another ranging from two to 20 years of age for both males and females. Percentile values less than the $5^{\text {th }}$ percentile or greater than the $95^{\text {th }}$ percentile warrant evaluation ${ }^{4}$.

Risk of malnutrition in children and infants becomes even more likely in the critically ill. As reported by Mahdavi et al. malnutrition, and in particular, undernutrition is a common finding in hospitalized patients, including hospitalized children ${ }^{17}$.

Overnutrition also becomes an issue. Overnutrition, or overfeeding is when the child is given more energy than the body utilizes which may lead to weight gain and possible obesity at an early age. This overfeeding has many complications as it can impair liver function by inducing steatosis, cholestasis, and an increase in the risk of infection secondary to hyperglycemia ${ }^{16}$. McKormick et al. concluded that morbidity related to obesity in infancy may be present from an early age ${ }^{18}$. Also recognizing the complications that come with obesity, Shibli et al. reported obese children may have 
higher rates of breathing problems and an increased rate of hospital admissions and readmissions ${ }^{19}$. As recorded by Mehta et al. "failure to provide optimal nutrients during this stage will result in exaggeration of existing nutrient deficiencies and in malnutrition, which may affect clinical outcomes" ${ }^{\prime 16}$. It can be seen that as with adults, proper nutrition assessment and the ability to accurately estimate a patient's energy needs is a vital component to a child, or infant's course of hospital care.

\section{Estimating Energy needs in Healthy Infants and Children}

Giving infants and children adequate nutrients is essential for their proper growth and development. As noted previously, none of the predictive energy equations were developed for use in children. The Dietary Reference Intakes (DRI) are utilized when estimating the energy needs of healthy children. The DRI's are nutrient intake standards for healthy people that were developed by the Institute of Medicine, a division of the National Academy of Sciences, in 1943 when nutritional deficiencies were more common. They are intended as reference values for most of the essential nutrients including carbohydrates, protein, fat, vitamins and minerals. These nutrient requirement levels are the amounts required daily to prevent deficiencies ${ }^{20}$. The DRIs also include estimated energy requirements in calories/day. This amount represents the intake to maintain energy balance and is based on age, gender, height, weight, and physical activity level. The DRIs are updated approximately every five years by highly qualified scientists with the best knowledge regarding essential nutrients and appropriate intakes. These references include values for all age ranges however; it is worth noting that they are only estimates of average nutrient requirements in a healthy population ${ }^{20}$. In a healthy infant or child, DRI standards are used to guide clinical care. Using the child's age, 
height, weight, and gender, a clinician can use the DRI to estimate energy requirements to sustain growth and development. The clinician would then monitor growth over time to assure adequacy of the child's intake.

When a child or infant is ill, these DRI values no longer represent appropriate energy guidelines. Different disorders and diseases cause the energy needs to be altered in children and infants. Understanding the nutritional needs of these children and the ability to provide adequate energy and nutrients is a vital piece of their clinical care.

Neurological Disorders and Nutrition

Neurological devastation is a term to describe the result of a neurological event so severe it results in brain damage. It has been defined as an abnormality in the central nervous system, manifested during the developmental period that results in lifelong disability in any of the physical, cognitive, sensory, speech and language, or neuropsychological functions ${ }^{21}$. There is wide range of damage that can occur causing immobility, lack of brain growth, and possible death. When a patient suffers an event that causes any neurological devastation, there is a range of clinical outcomes; neurological devastation can lead to death upon delivery or shortly after. It is also possible for a patient who has suffered any neurological devastation to live for a number of years with disabilities. There are many conditions that can lead to neurological devastation including, but not limited to, spinal muscular atrophy, cerebral palsy, hypoxic ischemic encephalopathy, and any other traumatic event to the brain during the delivery process.

\section{Spinal muscular atrophy}

Etiology: Spinal muscular atrophy (SMA) is a genetic disorder that causes progressive muscle degeneration that eventually leads to death. SMA is caused by mutations in the 
genes that make up the SMN protein which is important in the maintenance of motor neurons. SMA follows an autosomal recessive pattern, which means those affected carry two of the mutated genes ${ }^{22}$.

Epidemiology: SMA is listed as a Rare Disease by the National Institutes of Health, affecting 1 in 6,000 to 1 in 10,000 people. If affects less than 200,000 people in the U.S ${ }^{22}$. Signs and Symptoms: The level of severity for those affected with SMA is classified by numbers. Those with SMA suffer from motor neuron deterioration and muscular atrophy. This leads to progressive weakening of the muscles and eventually the loss of function. The time and progression of the disease is based upon the type of SMA. SMA type 1, also known as Werdnnig-Hoffman disease, is the most severe case of the disease. This type of SMA is apparent within six months of birth. Infants with SMA type 1 are born with very little muscle tone, weak muscles and feeding and breathing problems ${ }^{22}$. Medical Care: There is no treatment for those affected with SMA, and the prognosis for infants born with type 1 is usually no more than 2-3 years of life ${ }^{22}$. Nutritional Concerns: Infants with this disorder have issues with swallowing, feeding and handling of oral secretions. Also, their tongue my show signs of atrophy and fasciculation ${ }^{23}$. These features place infants with SMA at a greater nutritional risk and extensive nutritional support is necessary. In severe cases, enteral or parenteral nutrition support may be necessary.

\section{Cerebral Palsy}

Etiology: Cerebral palsy is another condition that affects the brain function of infants. There are several different types of cerebral palsy; however they are all caused by injuries or abnormalities of the brain. These injuries which can include bleeding in the brain, 
infections of the brain, head injury, or infections of the mother during pregnancy usually occur as the baby is growing within the womb.

Epidemiology: The prevalence of Cerebral palsy has risen over the last 40 years and now affects 2 out of every 1,000 live births. Areas of lower socio-economic status seem to have a higher prevalence of Cerebral Palsy ${ }^{24}$

Signs and Symptoms: The signs and symptoms of cerebral palsy can vary widely depending upon the individual affected. The damage to the brain causes these infants and children affected with cerebral palsy to have symptoms of abnormal movements; muscles and joints that will not stretch or open, abnormal gait, or loss of movement of an entire muscle group. Those with Cerebral palsy can also be affected by seizures, hearing and vision problems, generalized pain or decreased intelligence. The symptoms can range from mild to severe, can occur on one side of the body or both, and can either affect the arms, legs, or both. Symptoms are commonly seen within the first two years and as early as the first 3 months.

Medical Care: There is no cure for Cerebral Palsy. The treatment for those affected is to achieve the best functionality possible. Their medical team is made up of many members including primary care doctors, occupational, physical, and speech therapists, dietitians, social workers, and other specialists. The goal is for the individual to be as independent in activities of daily living as possible.

Nutritional Concerns: Those with Cerebral Palsy are at nutritional risk due to sucking difficulties as infants and dysphagia and chewing difficulties as they get older. Vomiting and constipation are also concerns among those that are affected by Cerebral Palsy ${ }^{25}$. In severe cases, enteral or parenteral nutrition support may be necessary. 


\section{Neonatal encephalopathy}

Etiology: Neonatal encephalopathy, or birth asphyxia, is the clinical manifestation of disordered neonatal brain function ${ }^{26}$. It is caused when the baby does not receive enough oxygen to the brain during delivery. There are numerous reasons why an infant might not receive enough oxygen during delivery, including, but not limited to, very long or difficult delivery, immature airway development, or nuchal cord during delivery ${ }^{27}$. Epidemiology: The risk factors for neonatal encephalopathy vary between different socioeconomic populations but include factors such as growth restriction in the womb, and twin pregnancy. The incidence of neonatal encephalopathy is estimated at 3 out of every 1000 live births ${ }^{28}$.

Signs and Symptoms: The amount of time that the baby goes without proper oxygenation is the key of damage severity. Some cases are severe enough to cause permanent brain damage or even death. Infants affected will exhibit an abnormal level of consciousness, seizures, tone and reflex abnormalities, apnea, aspiration, feeding difficulties and an abnormal hearing screen ${ }^{28}$.

Medical Care: Upon delivery, adequate resuscitation should be restored and $\mathrm{O} 2$ saturation should be kept above 95\%. Blood gases, glucose, urea, electrolytes, creatinine and fluid balance should be monitored by the medical team. The infant also undergoes a neurologic assessment and imaging assessments to assist with prognosis. Once stable, there is little the medical team can do to reverse any damage that has occurred ${ }^{29}$. Nutritional Concerns: When the worst case occurs and the infant suffers from permanent brain damage, they are likely to have the same risk factors for nutrition as infants born 
with the disorders previously discussed. Immobility and lack of muscle control can lead to nutrition related problems. In severe cases, enteral or parenteral nutrition support may be necessary.

\section{Zellwegger's Syndrome}

Etiology: Zellwegger's Syndrome, a peroxisome disorder, is part of a larger group of diseases known as leukodystrophies. These are inherited conditions that are caused by a defect in any one of 13 genes. These conditions damage the white matter of the brain and affect how the body metabolizes certain substances ${ }^{30}$.

Epidemiology: Zellewegger's syndrome is the most common of the peroxisome disorders. Its incidence rate has been estimated to be 1 in $50,000-100,000^{31}$. Signs and Symptoms: Infants born with Zellwegger's syndrome may suffer from neurologic abnormalities such as mental retardation and seizures. Wide set eyes, undeveloped eyebrow ridges, enlarged liver and lack of muscle tone are other characteristics associated with Zellwegger's syndrome ${ }^{30}$. Medical Care: There is no treatment or cure for Zellwegger's syndrome and therefore treatment is symptomatic and supportive. Most infants born with Zellwegger's have a life expectancy of less than 6 months of birth ${ }^{30}$.

Nutritional Concerns: The mental deterioration which is possible with Zellwegger's makes these infants and children at nutritional risk due to their inability to feed and possible risk for complications such as aspiration pneumonia. The level of nutritional support needed is dependent upon the severity of their mental deterioration. In severe cases, enteral or parenteral nutrition support may be necessary. 
These are just a few of the disorders that affect newborns that can lead to immobility and neurological devastation. There are many other disorders, and general head trauma that can cause these issues as well. Like other infants these babies cannot feed themselves, however, they are all at greater nutritional risk. The severity of their neurological devastation inhibits them from performing the most basic physiological functions related to eating. They are at risk for aspiration and choking due to the swallowing and chewing issues that accompany brain damage. Along with swallowing and chewing issues, they may suffer from gastrointestinal problems related to the defective neural control of their digestive tract ${ }^{32}$.

\section{Ethical Considerations}

Ethical concerns come into play when deciding whether artificial nutrition and hydration should be provided for these infants. Literature developed on the critical care of children, to provide treatment, to what degree, and length of time is limited ${ }^{32}$. Neurological devastation is one of the three categories from which case studies suggest it is ethically permissible to forego medically provided nutrition to children ${ }^{32}$. As children, their rights regarding artificial nutrition and hydration are exercised through their caregivers; however, if the medical staff can demonstrate that the caregivers are not acting in the best interest of the child the caregiver's authority can be over ruled ${ }^{33}$. It becomes the clinicians' job to make sure that the infant or child receives the most appropriate care while alive, regardless of the prognosis. As one study states, "the guiding principle is that treatment should be judged inappropriate if it adds nothing to the well-being of the child" ${ }^{34}$. 
When artificial hydration and nutrition are deemed appropriate, nutritional support methods via an enteral route are most often the course taken as they are the most appropriate method of feeding for the neurologically devastated infants and children.

Nutrition Support in the Neurologically Devastated Infant

Swallowing dysfunction, chewing difficulty or immobility and the physical inability to feed oneself are the complications that can accompany brain damage. As reported by Wadie in 2002, neurologically impaired children often demonstrate poor sucking ability, improper jaw, lip and tongue control along with uncoordination of oropharyngeal and tongue reflexes which cause defective swallowing. When these situations occur, medical nutrition support is indicated ${ }^{8}$.

For critically ill children with a functional gastrointestinal tract, enteral nutrition is the preferred mode of nutrient provision ${ }^{16}$. Enteral nutrition is feeding of the patient through a tube into the gastrointestinal tract and has been shown to be more cost-effective without the added risk of nosocomial infections that are commonly associated with parenteral nutrition ${ }^{16}$. There are various types of feeding tubes, and placements are dependent upon the need of the patient ${ }^{16}$. A nasogastric tube $(\mathrm{NG})$ is one that is inserted through the nose down into the stomach. This is considered to be a form of gastric feeding. The drawbacks of the NG tube are usually related to long term use and include risk of aspiration, nasopharyngeal irritation, and dislocation requiring frequent replacement ${ }^{35}$. Another form of gastric feeding is the gastrostomy tube ( $G$ tube). This type of feeding tube is one that is directly placed into the stomach from the outside of the body. This eliminates the nasopharyngeal irritation and the stigma of a tube from a 
patient's nose. The most common indication for a $\mathrm{G}$ tube placement is the need to bypass the organs of the upper gastrointestinal tract including the mouth or esophagus or when feeding is expected to be long-term ${ }^{8}$.

For children with gastric feeding complications, positioning of the tube postpyloricly, or past the stomach, may improve the patients' toleration of feeds ${ }^{16}$. Gastrointestinal blockage or anatomical abnormalities can be contraindications of gastric feeding ${ }^{35}$. By placing the tube further along the gastrointestinal tract, the risk for aspiration may be reduced. The patient's diagnosis, gastrointestinal function and the length of feeding guide the decision for location of tube placement. Studies have been completed to assess the safety of various feeding tube placements. As reported by Frolich, "percutaneous endoscopic gastrostomy insertion for enteral nutrition in a pediatric population is an efficient and safe technique even in children as small as $2.3 \mathrm{~kg}$ " 35 . The surgically placed gastrostomy tube has also been evaluated, and as concluded by Wadie, "laparoscopic placement of a low-profile GT in neurologically impaired children is a safe, simple, and well tolerated procedure." The enteral feeds can be given either continuously, or by bolus feeds. Although bolus feeds mimic natural meals, continuous feeds may be better tolerated ${ }^{8}$. The enteral route for nutritional support has been shown to successfully deliver nutrition support to critically ill children ${ }^{16}$.

After the placement of the feeding tube has been made, the medical team must decide upon the formula selection and technique. There are numerous formulas developed that are made up of different ingredients and levels of macronutrients targeted at specific patient needs. Some formulas are developed with special combinations of fatty acids which are thought to aid in inflammation. Other formulas contain ingredients such 
as glutamine and probiotics which have been shown to improve gut integrity. For patients less than a year old, infant formula or expressed breast milk is used for enteral feedings. Modular nutrients can be added to the enteral feedings based upon the patient's needs. The formula selection will be dependent upon the patient's medical situation and the most appropriate formula will be selected by the medical team.

The measured or estimated energy needs of the patient are also part of the formula selection. Enteral formulas all contain varying amounts of calories, protein, and fat. A clinician selects a formula and an amount that meets the patients' energy requirements and monitors the indices first collected at the initial assessment; weight, height, BMI and intake to analyze the appropriateness of the enteral feeding.

Estimating energy requirements of children with neurological disorders As stated by the ASPEN guidelines, "accurate assessment of energy requirements and provision of optimal nutrition support therapy through the appropriate route is an important goal of pediatric critical care" ${ }^{\prime 1}$. This statement is inclusive of all critically ill children and infants; however, there is a lack of research and evidence for accurately estimating the needs of critically ill children, especially those with neurological impairment. Children who suffer from neurological impairment have disease specific energy requirements that vary with the severity of their disability, their mobility and any presence of feeding difficulties ${ }^{36}$.

There is no set standard for the estimation of energy needs for critically ill children. The ASPEN guidelines even point out that estimating energy needs based on standard equations have been shown to be inaccurate and can significantly underestimate or overestimate the REE in critically ill children ${ }^{16}$. There seems to be a consensus among 
studies that the total energy needs of critically ill children, including those with neurological impairment are lower than the needs of healthy infants, and the values suggested by standardized equations ${ }^{36,37,38,39,40,41}$. Mehta et al. assessed the degree of underfeeding and overfeeding risk in critically ill infants and found that the use of standardized equations to assess energy overestimated the requirements needed by the study population. This study also found that the physicians overestimated the degree of metabolic stress in a majority of the patients which contributed to a high degree of overfeeding ${ }^{41}$. Another study, completed by Letton et al, corroborated these findings and declared that the actual energy expenditure in critically ill children of less than two years can be as little as $50 \%$ of their predicted requirements ${ }^{42}$. This most certainly would cause overfeeding if the predicted requirements were prescribed nutritionally. With similar findings, Chwals reported that, "the delivery of caloric amounts normally required for healthy infants is inappropriate for acutely-stressed, critically ill infants in whom total energy requirements are much lower due to inhibited growth, reduced insensible losses, and decreased activity"43.

This decreased activity is even more pronounced when dealing with a population of infants who are neurologically devastated and therefore completely non-ambulatory. These patients often present with altered muscle tone in the form of spasticity or hypotonia. These physical states alter the metabolism and the needs of these patients $\mathrm{s}^{37,39}$. In one review regarding the nutritional management of the neurologically impaired child, is it stated that the DRI's are often used to estimate calorie needs. However, even when used without any physical activity coefficient, these equations overestimate the calorie needs of the neurologically impaired child ${ }^{44}$. 
In contrast, the Brain Trauma Foundation recommends that infants and children who have suffered a brain injury are in need of $130-180 \%$ of predicted energy needs based on data from 19 patients in 2 studies. They do, however, point out that there is a lack of data on energy needs in this population and emphasize these are recommendations not guidelines ${ }^{45}$.

Because of the wide array of neurological disorders that can affect mobility and nutritional status it is hard to complete studies that encompass this entire population. Bandini et al. aimed to determine the energy needs of a population of individuals with severe central nervous system disorders. Their study confirmed that resting metabolic rate was significantly lower in these individuals than the value predicted by equations ${ }^{37}$.

Spastic quadriplegic cerebral palsy (SQCP) is an example of a common permanent, severe disability usually with marked decreased cognition and ambulation ${ }^{38}$. This type of cerebral palsy has been used in at least two later studies as a model for neurological devastation. These studies have concluded energy requirements of children and infants with SQCP are significantly lower than expected. The first of these studies, which compared REE by indirect calorimetry of children with SQCP and normal children of the same age, found that the REE in SQCP children was significantly less than in control subjects and also lower than the value from predictive equations ${ }^{39}$. The second study compared patterns of energy expenditure in normal children and those with SQCP. This study also found that the SQCP group had values significantly lower, by $694 \mathrm{kcals}$, than the control group in total energy expenditure ${ }^{38}$.

Although these few studies come to similar conclusions, there is a major lack of research in the area of energy needs for neurologically impaired children. This lack of 
systematic research and clinical trials creates a challenge when attempting to apply any evidenced based guideline for nutrition support ${ }^{36}$. Monitoring the rate of weight gain and growth in response to nutritional therapy is the best way to determine adequacy of the diet $^{36}$. There is a growing need for studies to be completed on groups of infants and children who are suffering from specific neurological impairments in order to attain appropriate information regarding their energy needs. Without these studies, the risk of overfeeding or underfeeding and the complications that come with them are unavoidable. It is imperative for more studies to be completed analyzing the energy needs versus the energy intakes and the clinical outcomes in a population of neurologically devastated infants and children. 


\section{Chapter 3: Methodology}

Energy expenditure in a person is drastically affected by the amount of work done by the muscles in the body. Brain function, especially during the formative years, also contributes to the energy needs of individual ${ }^{2}$. It is crucial to evaluate the current level of care for neurologically devastated infants and children so that the appropriate nutrition support can be determined. Without any specific reference to guide nutrition therapy, they are at a greater nutritional risk of both undernutrition and overnutrition. Under nutrition affects the body's processes of healing, growth, and immune function. Over nutrition can lead to excessive weight gain that may lead to metabolic complications and can make daily care more difficult. The purpose of this study was to gain a better understanding of the typical nutritional care of neurologically devastated infants and children and offer implications for future research.

Patients that have little or no functioning in their muscles or brain require an altered amount of energy from those without medical complications. These include but are not limited to, those diagnosed with spinal muscular atrophy, cerebral palsy, neonatal encephalopathy, and any other conditions of neurological or neuromuscular devastation. The clinical assumption would be that these individuals would require an altered amount of energy due to lack of movement. However, at this time there are no equations or predictive methods of estimating energy needs for these types of individuals. Physicians 
and Registered Dietitians who prescribe the energy intake for these individuals are operating primarily by extrapolation from clinical practice precedent or information from similar pediatric diagnoses. This study focused on children affected by neurological disorders and their medical and nutritional history. Qualitative analysis of information from past medical records was the basis of this descriptive study.

\section{Research Design}

The design of this study was a retrospective descriptive analysis for a sample of neurologically devastated children admitted to a Midwestern children's medical center. The data for this study was gathered from medical records of patients admitted from 2006 to June 2011. This study was an exploratory study aimed at investigating the energy provided from nutrition support to a group of neurologically impaired children and its effect on specific variables, including calories provided and growth patterns. Although the focus of this study is narrow, its implications may have broad possibilities and application.

\section{Limitations}

As an exploratory study focusing on specific variables, this study has limitations. It is possible that not all the medical records reviewed contained the information or variables that the study wished to analyze. This missing data may have an effect on the study outcomes. Also, a majority of the patients studied have multiple co-morbid conditions and other factors that may play a role in the variables being investigated. For the purposes of this study, no other conditions and factors were included into the analyses. This study aimed to provide a basic framework of energy provision and its relation to growth patterns for future studies to build upon. 


\section{Research Questions}

1. What was the average age of patients upon admission to the hospital?

2. Upon initiation of enteral feedings, what was the average kilocalories per kilogram of body weight $(\mathrm{kcal} / \mathrm{kg})$ provided daily? What was the average grams of protein per kilogram of body weight $(\mathrm{g} / \mathrm{kg})$ provided daily?

3. What was the average weight for length percentile of the children at the initiation of enteral feedings?

4. How did the weight for length percentile of the children at the initiation of tube feedings compare to the weight for length percentile of the children at their last assessment and/or 6 months post initiation of enteral feedings?

5. What is the growth pattern for this sample of children over their lifespan and or a period of 6 months post initiation of enteral feedings as measured by weight gain and increase in height?

\section{Sample Selection}

The sample of convenience includes patients admitted to the hospital that meet the inclusion criteria for the study. The inclusion criteria include admission to the hospital from the year 2006 to June 2011, a diagnosis of a neurological disorder at birth or within the first year of life requiring nutrition support, and the presence of dietetic intervention in the child's medical support team evidenced by dietetic progress notes in the medical records. Using these criteria, a sample of 24 patients has been included in the descriptive analysis of this study. 


\section{Data Analysis and Instrumentation}

The data was collected from the medical record of the patient. The collected data was organized into a data collection template specific to this study. (See Appendix A) The collected data was then analyzed in order to answer and discuss the proposed research questions. Descriptive statistics were analyzed for questions 1-3. Question four was answered using a paired t-test and question 5 was answered by qualitative analysis. 


\section{Chapter 4: Results and Discussion}

A retrospective chart review of 24 neurologically devastated infants was conducted to determine patterns of growth and energy intake in this population. A list of 80 patients was generated and of that list, 24 met the criteria for inclusion in the analysis including 14 males and 10 females. Data collected included age at admission, diagnoses, weight, length, kilocalories per kilogram of body weight $(\mathrm{kcal} / \mathrm{kg})$, grams of protein per kilogram of body weight $(\mathrm{g} / \mathrm{kg})$, changes made to the nutrition prescription, and weight for length percentile. These variables were used to identify patterns in the amount of energy provided to this population and the resulting growth of these infants. This selection of patients included a range of neurological diagnoses and outcomes.

\begin{tabular}{|lc|}
\hline \multicolumn{1}{|c|}{ Diagnoses } & $\boldsymbol{n}$ \\
\hline Brain Anomalies & 6 \\
\hline Cerebral Palsy & 5 \\
\hline Spinal Muscular Atrophy & 3 \\
\hline Neonatal Encephalopathy & 6 \\
\hline Seizures that led to brain damage & 3 \\
\hline Zellwegger's Syndrome & 1 \\
\hline
\end{tabular}

Table 2: Diagnoses included in data analysis 
The primary research questions were:

1.) What was the average age of patients upon admission to the hospital?

2.) Upon initiation of enteral feedings, what was the average kilocalories per kilogram provided? What was the average grams of protein per kilogram provided?

3.) What was the average weight for length percentile of the infants upon the initiation of enteral feedings?

4.) How did the weight for length percentile of the infants at the initiation of enteral feeds compare to the weight for length percentile of the infants at their last assessment and/or 6 months post initiation of enteral feedings?

5.) What is the growth pattern for this sample of children over their lifespan and or a period of 6 months post initiation of enteral feedings as measured by weight gain and increase in height?

\section{Results}

Analysis of variables using descriptive statistics was utilized to answer questions 1-3. The average age upon the admissions that were included was 1.9 months. Upon initiation of enteral feedings, the average kilocalorie per kilogram and grams of protein per kilogram provided were 93.38 and 1.4 respectively. The average weight for length percentile upon admission was 34.92 percentile. Data from all 24 patients were used in the analysis; however, data regarding protein intake was limited and may not reflect results from all 24 patients. (See table 3 ) 


\begin{tabular}{|lllll|}
\hline & Minimum & Maximum & Mean & \multicolumn{1}{c|}{$\begin{array}{c}\text { Std. } \\
\text { Deviation }\end{array}$} \\
\hline $\begin{array}{l}\text { Age upon } \\
\text { Admission(months) }\end{array}$ & $0(\mathrm{birth})$ & 13 & 1.9 & 3.17 \\
\hline $\begin{array}{l}\text { Average kilocalories per } \\
\text { kilogram body weight } \\
\text { provided }\end{array}$ & $43 \mathrm{kcal} / \mathrm{kg}$ & $144 \mathrm{kcal} / \mathrm{kg}$ & $93.38 \mathrm{kcal} / \mathrm{kg}$ & $34.94 \mathrm{kcal} / \mathrm{kg}$ \\
\hline $\begin{array}{l}\text { Average grams protein } \\
\text { per kilogram bodyweight } \\
\text { provided }\end{array}$ & $.50 \mathrm{~g} / \mathrm{kg}$ & $2.8 \mathrm{~g} / \mathrm{kg}$ & $1.4 \mathrm{~g} / \mathrm{kg}$ & $.69 \mathrm{~g} / \mathrm{kg}$ \\
\hline $\begin{array}{l}\text { Weight for Length } \\
\text { percentile }\end{array}$ & $0-3$ & & & \\
\hline & percentile & percentile & $\begin{array}{l}\text { percentile } \\
\text { percentile }\end{array}$ \\
\hline
\end{tabular}

Table 3: Description of subjects at initial assessment

The fourth research question was answered using a paired t-test to compare the difference in weight for length percentiles upon initiation of enteral feeds and on their last assessment. Due to the variation of time intervals between progress documentation only 20 of the 24 subjects were included in this analysis. The average weight for length percentile upon initiation of enteral feeds was 36 and the average weight for length percentile of their final assessment was 50 . The results of the paired t-test indicate a significant difference in the weight for length percentiles from the start of enteral feeds to the last assessment. $(\mathrm{p}=0.048)$

\section{Patterns of growth and energy provision}

The data was used to investigate patterns between the growth of the patients, measured by weight for length percentiles, and the $\mathrm{kcal} / \mathrm{kg}$ they were receiving. The 24 patients whose data were collected fell into four different groups based on their patterns 
of growth. There was not a group that made up the majority; in contrast, the 24 patients were split almost evenly between the groups. The first group was classified by highly variable growth with little predictability in response to feedings. The second group was characterized by fairly predictable growth patterns in response to feedings. The third group of infants showed little or no growth and the last group of infants was characterized by what appeared to be hypometabolism, showing growth on lower than average amounts of $\mathrm{kcal} / \mathrm{kg}$.

Group one exhibited growth patterns and energy provision that lacked any consistency. The data on these infants were too variable to highlight any type of trend or pattern. A few of the infants in this group have data values that are questionable and may be the result of human error in documentation. The documentation on one patient was not consistently clear whether they were on or off parenteral nutrition (PN) and this could have affected the true $\mathrm{kcal} / \mathrm{kg}$ provided. Within this group there are also infants whose data was too limited to provide for any evaluations or conclusions. Although no solid analysis can be completed on these infants as their data is too variable and some variations in the data may be caused by human error, the mere presence of such a high amount of variation in their energy needs related to their growth profiles is noteworthy.

The second group was made up of patients whose growth followed patterns that one would expect; growth increases with increased feeds, and growth drops with decrease in feedings. These infants exhibit growth responses that are consistent with the pattern of growth for a normal infant. Figure 1 shows graphically the growth pattern seen by an individual representative to this group. 


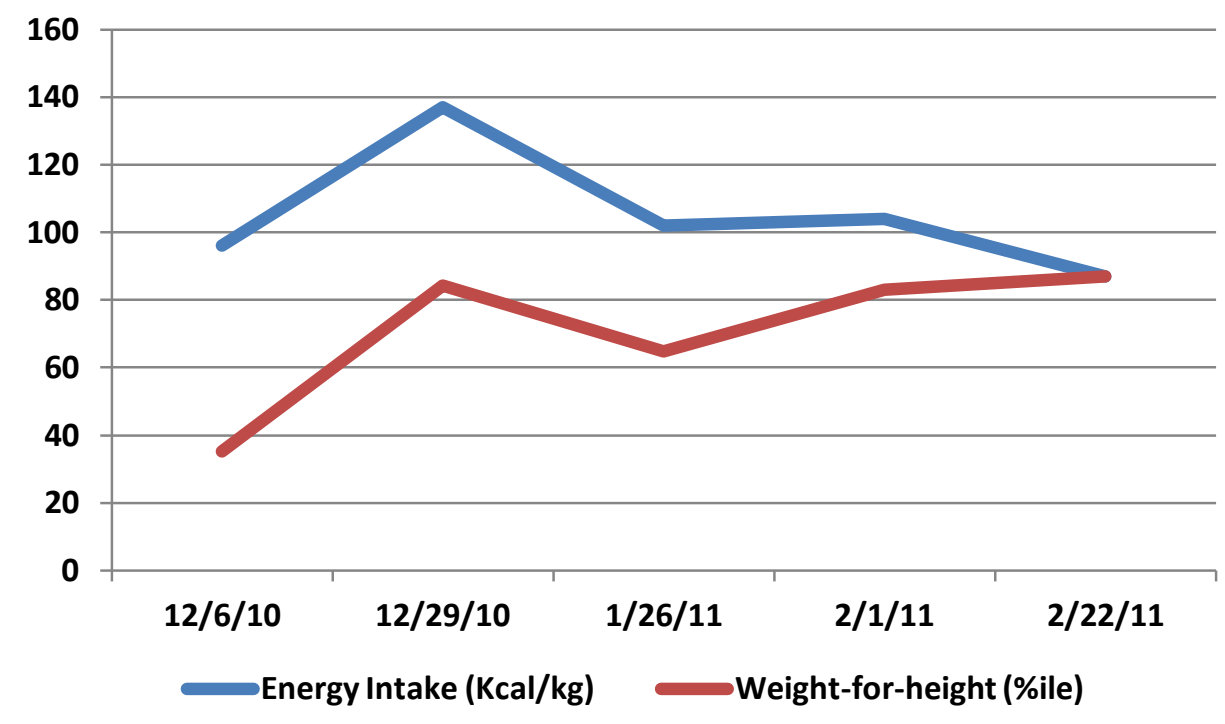

Figure 1: Kcal $/ \mathrm{kg}$ versus weight for length $\%$

The third group was made up of 6 patients who showed little to no growth regardless of the energy provided. Five patients out of the six maintained growth below the $10^{\text {th }}$ percentile with no response to increasing the amount of $\mathrm{kcal} / \mathrm{kg}$ provided. This group represents a selection of what appears to be hypermetabolic infants that may require increased caloric amounts to reach their full growth potential. Figure 2 highlights the growth pattern exhibited by this group as represented by one individual's growth progress. 


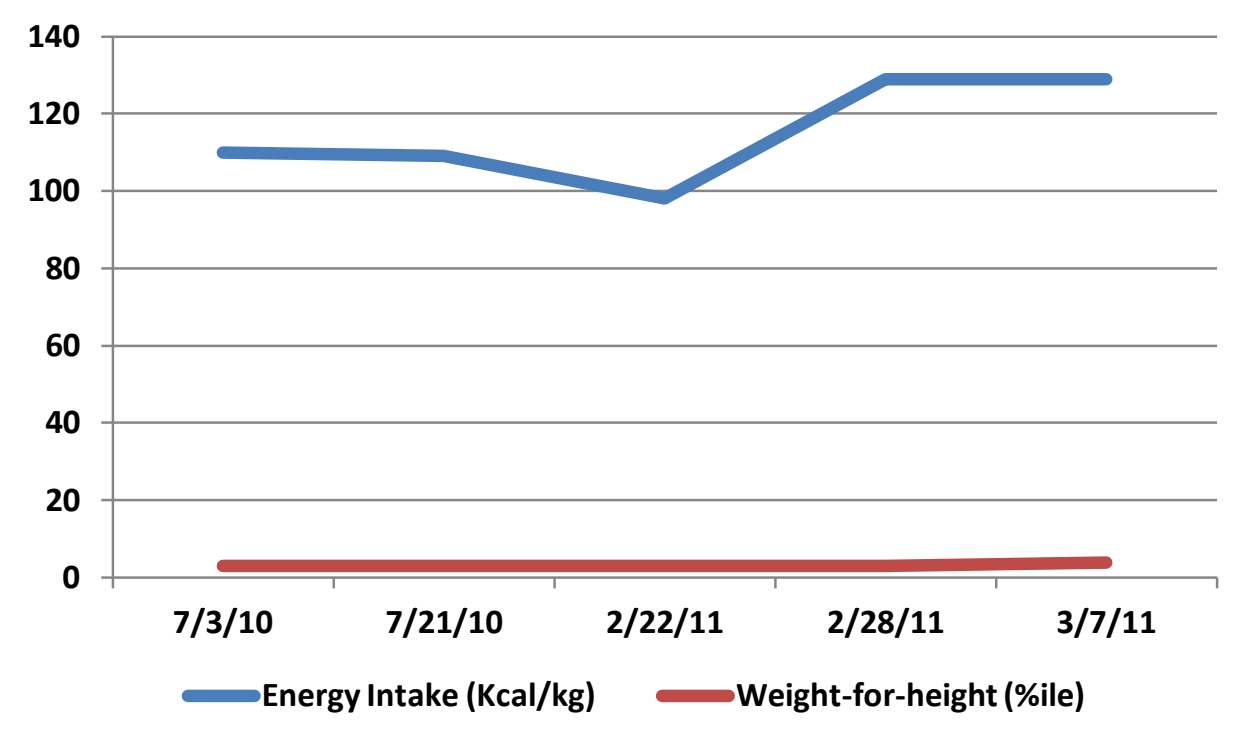

Figure 2: Kcal $/ \mathrm{kg}$ versus weight for length $\%$

The individual represented in Figure 2 suffered from nuchal cord and was admitted at birth. This infant was below the $3^{\text {rd }}$ weight for length percentile at birth and was initially started on feeds of $110 \mathrm{kcal} / \mathrm{kg} / \mathrm{day}$; an amount near the higher end of the required infantile calorie range of $80-120 \mathrm{kcal} / \mathrm{kg}^{13}$. This infant was followed weekly in the hospital and was documented to have been receiving $110 \mathrm{kcal} / \mathrm{kg} /$ day consistently for a month with no growth above the 3rd weight for length percentile. After being discharged and readmitted six months later, this infant was still below the $3^{\text {rd }}$ weight for length percentile and no increase in growth was seen on feeds that were increased to $130 \mathrm{kcal} / \mathrm{kg} /$ day.

The remaining five infants make up the last group characterized by what appears to be hypometabolism. The infants in this group exhibited growth on calorie intakes below their predicted needs. Some infants in this group showed patterns of extreme 


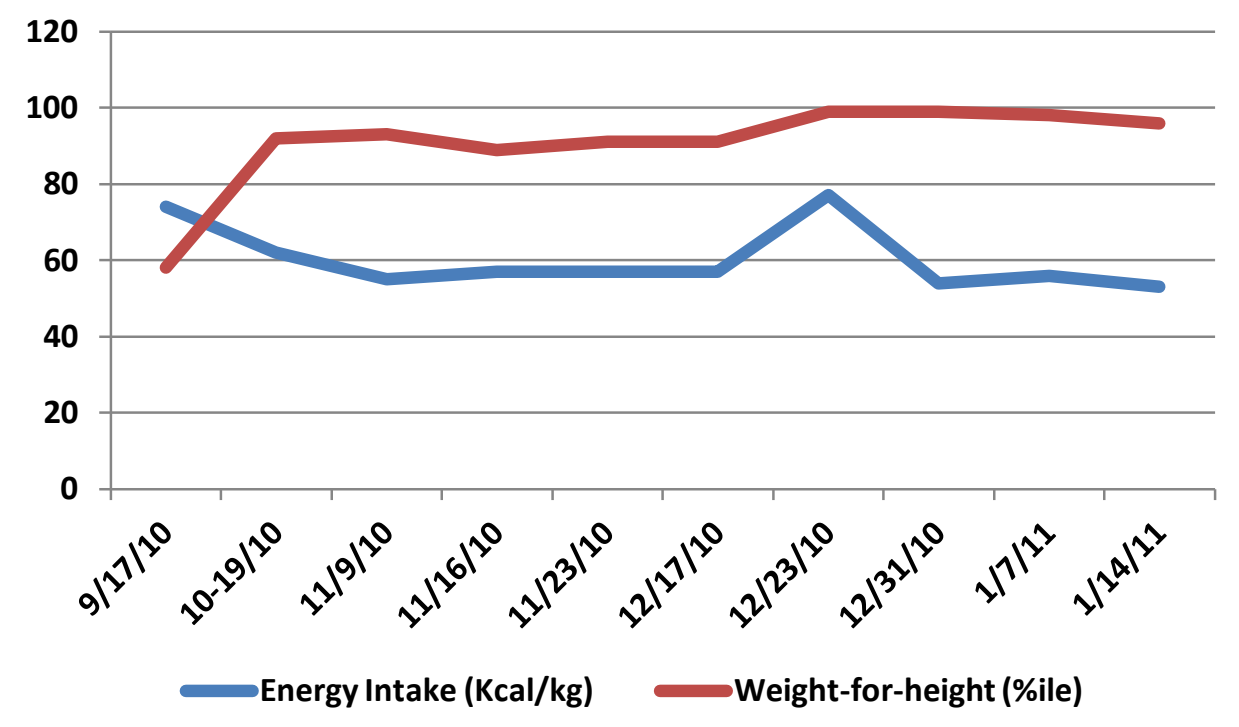

Figure 3: Kcal $/ \mathrm{kg}$ versus weight for length $\%$

growth even while their caloric intakes were limited. Four of the five infants had growth into and above the $90^{\text {th }}$ percentile while receiving lower than average $\mathrm{kcal} / \mathrm{kg}$ values. This pattern of growth is represented below in figure 3 .

The individual represented in Figure 3 was admitted at birth and suffered from hydranencephaly. At birth, the infant was at the $54^{\text {th }}$ weight for length percentile and was given a goal of $110 \mathrm{kcal} / \mathrm{kg} / \mathrm{day}$. Three months later, the infant had grown into the $92^{\text {nd }}$ weight for length percentile, even after the feeds had been decreased to $80 \mathrm{kcal} / \mathrm{kg} /$ day a month prior. This infant's weight for length percentile continued at or above the $90^{\text {th }}$ percentile even as the feeds were continuously decreased. The feeds were decreased to a low of $50 \mathrm{kcal} / \mathrm{kg} /$ day; $30 \mathrm{kcal} / \mathrm{kg}$ below the low end of the required caloric range of $80 \mathrm{kcal} / \mathrm{kg}$ for infants. This individual exhibits a growth pattern consistent with hypometabolism. 
Another individual who illustrated possible hypometabolism was admitted at birth in the $60^{\text {th }}$ weight for length percentile. Feeds were initiated at $100 \mathrm{kcal} / \mathrm{kg}$ and were consistently between $100-110 \mathrm{kcal} / \mathrm{kg} / \mathrm{day}$ for a period of one month. During this period the infant grew into the $90^{\text {th }}$ weight for length percentile. The feeds were then decreased weekly from 70 , to 65 , to $50 \mathrm{kcal} / \mathrm{kg} /$ day. Even with the decrease in calories provided the infant reached growth into the $99^{\text {th }}$ weight for length percentile. This infant is another example of the characteristics normally associated with hypometabolism.

\section{Discussion and Conclusion}

The National Academy of Sciences developed the daily recommended intakes for medically stable infants in the first 6 months. The average caloric need to promote healthy growth is established to be $108 \mathrm{kcal} / \mathrm{kg}$. Caloric needs in medically stable infants usually ranges between $80-120 \mathrm{kcal} / \mathrm{kg}^{13}$. In this study the range of calories provided, 43$144 \mathrm{kcal} / \mathrm{kg}$, was much broader. For protein, the average recommended intake for infants up to 6 months is around 2.2 grams of protein $/ \mathrm{kg}^{13}$. In this study the average grams of protein provided was slightly lower than the average in medically stable infants. The results of this study show a pattern of unpredictability in energy needs and metabolic rates of children with neurological devastation.

There was no clear pattern of hypo or hypermetabolism seen in this selection of 24 patients. The variation in growth patterns exemplified by these 24 individuals is a strong indicator that there is limited ability to standardize energy needs for a population such as this. The amount of calories required to sustain and promote healthy growth is extremely different from one individual to the next. 
Some studies such as those completed by Mehta ${ }^{41}$ and Chwals ${ }^{43}$ have shown patterns of low metabolic rates in neurologically devastated infants, however, this study does not fully support these findings. Rather, this study supports the idea of extreme variation in the energy needs of neurologically devastated infants. This extreme variation makes evident how standardized equations and formulas for energy needs are inappropriate and most likely highly inaccurate for the neurologically devastated infant. While some of these infants would grow appropriately on the $108 \mathrm{kcal} / \mathrm{kg}$ average for medically stable infants, some require much higher or lower amounts. Almost half of the infants showed characteristics of hypermetabolism or hypometabolism indicating that there may be a substantial population whose energy requirements are far from standard. Use of such general formulas for energy provision increases the likelihood of malnutrition and overnutrition in this population. The variation among individuals also highlights the need to treat each patient on an individual basis. The Registered Dietitian should play an important role in developing specialized nutrition plans for these individuals. The needs of these individuals cannot be generalized or estimated using references from a normal population. It is extremely important to develop nutrition plans on a case by case basis in order to understand and provide the most accurate nutrition.

As stated earlier, the use of predictive equations and formulas for energy needs are most likely highly inaccurate for this population. The variation seen amongst the 24 patients in this study indicate that there may be no significant pattern, normal or not, of energy needs and therefore no strong evidence for the use of predictive methods. Methods such as indirect calorimetry which can more accurately measure the metabolic rate of an individual should be considered as the standard method of calculating energy 
needs in this population. In developing individualized nutrition plans for the patients, indirect calorimetry can be used for a more accurate picture of the patients needs. There is no way to predict the metabolic response in a patient with neurological devastation and because of this, indirect calorimetry must become a required component in their medical care if proper nutrition is to be provided.

\section{Limitations}

This study focused primarily on the growth patterns and the nutrition prescription provided to a selected population. There were multiple factors of the patients' medical histories that were not considered in this study. Factors such as medications, laboratory values, and other diagnoses were not included in the analysis of the data. These factors are capable of having a major influence on growth patterns and energy needs in patients. This exploratory study aimed to initiate the process of understanding the metabolic needs in the population of neurologically devastated infants. This researcher recognizes the need for further research that includes the factors that were not included in this study.

The number of patients included in this study is small and is therefore another limitation on the study results. Stronger or even different results may have been seen if there was a larger population studied. Along with the small number of patients, the collection of information from the progress notes of dietitians is also a limitation for this study. There was not a method to review the physicians' diet orders and not all patients reviewed had nutrition documentation. Only when the patient was followed by a dietitian was the information on their diet accessible. The ability to see both the physicians' and the dietitians' documentation on nutrition may have given a better picture as to the actual nutrition prescription of the patients. The results of this study must consider human error 
in documentation and collection, and also discrepancies and inconsistencies among the nutrition documentation. As a retrospective chart review, this study was only able to gather information that was at one time collected and documented on the patient. The results therefore may have been affected by any missing data or information in the medical record and dietetic progress note.

Future research should be conducted in the absence of the limitations presented in order to further the understanding of energy needs in neurologically devastated infants. Prospective monitoring of neurologically devastated infants may be able to greatly improve our understanding of their energy needs. Also, studies involving cluster analysis may provide a better profile of patients which would allow clinicians to better establish clinical care. 
Chapter 5: A Retrospective Chart Review: Nutrition Support in the Neurologically Impaired Child

\author{
Courtney Strauss \\ B.S. Biology \\ The Ohio State University \\ Marcia Nahikian-Nelms \\ $P h D, R D, L D, C N S C$ \\ The Ohio State University \\ Lynda Peel \\ $M A, R D, L D$ \\ Nationwide Childrens' Hospital \\ Jill Clutter \\ PhD, MCHES \\ The Ohio State University
}




\begin{abstract}
Background: Maintenance of energy balance is a crucial component of nutrition status in order to avoid malnutrition or overnutrition. For a healthy individual, energy needs can be predicted using various equations, however, in medically fragile populations these equations can be inaccurate. Neurologically devastated infants are a population that is especially vulnerable to inaccuracies due to the limited data on their metabolic response. There are no standards as of yet to accurately predict the amount of energy this population needs. This study aims to investigate any patterns found between energy provision and growth in a population of neurologically devastated infants. Materials and Methods: Data was collected from medical records and analyzed. Specific variables that were collected include; diagnoses, sex, age at admission, weight, length, and kilocalories and grams of protein per kilogram of bodyweight. Variables were analyzed both qualitatively and quantitatively. Results: 24 patients were included in the analysis. No significant pattern or trend was found between energy provision and growth. Six patients demonstrated characteristics of hypermetabolism with little to no growth above the $3^{\text {rd }}$ weight for length percentile. Five patients demonstrated characteristics of hypometabolism with growth above the $90^{\text {th }}$ weight for length percentile on lower than average amounts of kilocalories per kilogram of bodyweight. The remaining 13 patients showed either high variability in growth or predictable patterns expected with normal metabolism. Conclusion: This population of neurologically devastated infants illustrates the need for individualized nutrition plans and use of indirect calorimetry over predictive equations to ensure accurate energy amounts are provided.
\end{abstract}




\section{Introduction}

Nutritional status is an important determinant of the clinical outcomes for critically ill patients. Malnutrition negatively impacts medical status and has been associated with longer hospital stays ${ }^{1}$. In the clinical setting, malnutrition is associated with increased infection risk, decreased healing rates and altered cell function ${ }^{2}$. As part of the medical team, registered dietitians are responsible for assessing a patient and developing a nutrition plan that meets the patient's needs. High risk individuals are identified by nutrition assessment data and specific interventions are determined to support the patient. For some patients, nutritional interventions are problematic as it is more difficult to estimate optimal energy requirements that will support the nutrition plan. Age, diagnosis, gender, activity and body composition all impact metabolism and energy needs of a patient. There are numerous methods that have been developed to measure a patient's energy needs. Energy requirements are estimated by measuring a patients resting energy expenditure (REE) which is the energy necessary to keep vital organs such as the heart, brain, liver and kidney functioning ${ }^{3}$. Direct calorimetry is a highly accurate method of using a sealed chamber to measure the amount of heat given off by the body. This amount of heat can then be used to measure REE. While accurate, this method is not practical to use in the clinical setting ${ }^{4}$. Indirect calorimetry is a method of measuring REE by analyzing the oxygen and carbon dioxide concentrations in expired air of a patient. Although more convenient and realistic to perform in the clinical setting the use of indirect calorimetry is still limited. In adults, the most common means of measuring REE is predictive equations. Factors including but not limited to age, height, weight, and activity are used mathematically to predict an individual's REE. In children, 
energy needs are estimated using the standards developed by the Institute of Medicine, a division of the National Academy of Sciences. These values known as the Dietary Reference Intakes (DRI) represent the amounts required daily to prevent deficiencies of essential nutrients such as carbohydrates, protein, fat, vitamins and minerals ${ }^{5}$. In a healthy infant, these DRI values help guide clinical care, however, when a child or infant is ill these DRI values no longer represent appropriate energy guidelines ${ }^{5}$.

Neurologically devastated infants represent one of the critically ill populations who are not only vulnerable to the effects of malnutrition but also pose a difficult situation for nutrition assessment. Neurological devastation includes a range of neurological disorders that result in brain damage. Damage to the brain can cause immobility, lack of brain growth and is often fatal. These individuals can have a broad range of energy needs showing characteristics of both hypo and hypermetabolism dependent upon their possible immobility and lack of brain activity. Children who suffer from neurological impairment have disease specific energy requirements that vary with the severity of their disability, their mobility and any presence of feeding difficulties ${ }^{6}$. Using standard predictive equations or values can be inaccurate and significantly underestimate or overestimate the REE of critically ill children ${ }^{7}$.

There is limited research for providing nutritional care for this population. Mehta et al. conducted a study aimed to identify the degree of underfeeding and overfeeding risk in critically ill infants. They determined that the use of standardized equations to assess energy needs overestimated the requirements for their study population ${ }^{8}$. Additional research, completed by Letton et al, corroborated these findings and declared that the actual energy expenditure in critically ill children of less than two years can be as little as 
$50 \%$ of their predicted requirements ${ }^{9}$. With similar findings, Chwals reported that, "the delivery of caloric amounts normally required for healthy infants is inappropriate for acutely-stressed, critically ill infants in whom total energy requirements are much lower due to inhibited growth, reduced insensible losses, and decreased activity" ${ }^{10}$. In contrast, the Brain Trauma Foundation recommends that infants and children who have suffered a brain injury are in need of 130-180\% of predicted energy needs based on data from 19 patients in 2 studies. They do, however, point out that there is a lack of data on energy needs in this population and emphasize these are recommendations not guidelines ${ }^{11}$. The lack of systematic research and clinical trials creates a challenge when attempting to determine evidenced based guidelines for nutrition support ${ }^{6}$ The purpose of this study was to gain a better understanding of the routine nutritional care of neurologically devastated, immobile, enterally fed infants and children.

\section{Methods}

The design of this study was a retrospective descriptive analysis for a sample of neurologically devastated children admitted to a Midwestern Children's Medical Center. The inclusion criteria included admission to the hospital from the year 2006 to June 2011, a diagnosis of a neurological disorder at birth or within the first year of life requiring nutrition support, and the presence dietetic intervention in the child's medical support team evidenced by nutrition progress notes in the medical records. Data collected from the medical record included age at admission, weight, length, diagnosis, sex, kilocalories per kilogram $(\mathrm{kcal} / \mathrm{kg})$ provided daily and weight for length percentile. Qualitative 
analysis was completed to investigate any trends or patterns between energy provision and growth patterns of this population. Approval for this study was attained from the hospital's Institutional Review Board.

\section{Results}

A total of 24 patients were included in this study. The diagnoses included brain anomalies, cerebral palsy, spinal muscular atrophy, neonatal encephalopathy, seizures that led to brain damage, and Zellwegger's syndrome. (See Table 4) The average age upon admission was 1.9 months. Upon initiation of enteral feedings, the average kilocalorie per kilogram and grams of protein per kilogram provided were 93.38 and 1.4 respectively. The average weight for length percentile upon admission was 34.92 percentile. The average weight for length percentile upon initiation of enteral feeds was 36.67 and the average weight for length percentile of their final assessment was 50.73 . (See table 5) The results of the paired t-test indicate a significant difference in the weight for length percentiles from the start of enteral feeds to the last assessment. $(p=0.048)$

The growth patterns exhibited by the 24 patients were highly variable. Categories describing the growth patterns of the infants emerged from the data. (See table 6) Group one exhibited highly variable data with little consistency among the infants. Data from this group may have reflected human error in documentation. Group two consisted of patients whose growth patterns were predictable and followed patterns that healthy infants would typically present. (See figure 4) Their growth responses matched their changes in feedings; increases in feeds led to increased weight and decreases in feeds led to weight loss. The third group, including six infants, showed little to no growth regardless of the energy provided. (See figure 5) Five of the six infants maintained 
growth below the $10^{\text {th }}$ percentile with no increase in growth in response to increased feeds. This group exhibits what appears to be hypermetabolism. The fourth group, made up of the last five infants, demonstrated weight gain on calorie intakes below their predicted needs. (See figure 6) Four of the five infants showed growth into or above the $90^{\text {th }}$ percentile while receiving markedly low $\mathrm{kcal} / \mathrm{kg}$ values. This group exhibited what appears to be hypometabolism.

\section{Discussion}

The growth patterns exhibited by these 24 individuals were highly variable. There was no clear pattern of hypo or hypermetabolism illustrated. The average caloric need to promote healthy growth is established to be $108 \mathrm{kcal} / \mathrm{kg}$. Caloric needs in medically stable infants typically range between $80-120 \mathrm{kcal} / \mathrm{kg}^{12}$. In this study the amount of calories provided, 43-144 kcal $/ \mathrm{kg}$, was much broader. The results of this study show a pattern of unpredictability in energy needs and metabolic rates of children with neurological devastation. This unpredictability and variation is a strong indicator that there is limited ability to standardize energy needs for a population such as this. The amount of calories required to sustain and promote healthy growth is extremely different from one individual to the next. Some studies such as those completed by Mehta ${ }^{8}$ and Chwals ${ }^{10}$ have shown patterns of low metabolic rates in neurologically devastated infants, however, this study does not fully support these findings. Rather, this study supports the idea of extreme variation in the energy needs of neurologically devastated infants. This extreme variation makes evident how standardized equations and formulas for energy 
needs are inappropriate and most likely highly inaccurate for the neurologically devastated infant. Use of such general formulas for energy provision increases the likelihood of malnutrition and over nutrition in this population.

The extreme variation among these infants highlights the need to treat each patient individually. The Registered Dietitian should play an important role in developing specialized nutrition plans for individuals of this population. The needs of these individuals cannot be generalized or estimated using references from a normal population. It is extremely important to develop nutrition plans on a case by case basis in order to understand and provide the most accurate nutrition. The variation seen amongst the 24 patients in this study indicate that there may be no significant pattern, normal or not, of energy needs and therefore no strong evidence for the use of predictive methods. Indirect calorimetry which can more accurately measure the metabolic rate of an individual should be considered as the standard method of calculating energy needs in this population.

\section{Limitations}

This study has limitations including its small size and its retrospective design. Only data that was present in the medical record was available for analysis; any missing data may have affected the results of this study. Also, this study was narrowly focused on growth patterns and their response to the nutrition prescription. There were multiple factors such as medications, laboratory values, and co morbid diagnoses that were not considered in this study. These factors are capable influencing growth patterns and energy needs. There is need for further research that includes these factors and the ability to actively collect data as it is being recorded. 


\section{Conclusions}

In a population of neurologically devastated infants, use of predictive methods for energy needs can be inaccurate and lead to malnutrition or overfeeding. A more accurate and personalized method of measuring REE is an important factor in the proper nutritional care of neurologically devastated infants. Registered dietitians should be proactive members of the medical team and evaluate each patient individually. Methods such as indirect calorimetry which can be performed on an individual basis can more precisely determine each patient's needs and will help guide their clinical care with a more accurate estimation of energy needs. 


\section{Article References}

1.) Kyle UG, Coss-Bu JA. Nutritional assessment and length of hospital stay. CMAJ. November 2010; 182(17):1831-1832.

2.) Khorasani EN, Mansouri F. Effect of early enteral nutrition on morbidity and mortality in children with burns. Burns. December 2009;36(2010):1067-1071.

3.) Nelms M, Sucher K, Long S. Nutrition Therapy and Pathophysiology. Belmont, CA: Thomson Higher Education; 2007.

4.) Lee RD, Nieman DC. Nutritional Assessment. $4^{\text {th }}$ ed. New York: The McGraw-Hill companies; 2007.

5.) McGuire M, Beerman K. Nutritional Sciences: From Fundamentals to Food. Belmont, CA: Thomson Higher Education; 2007.

6.) Marchand V, Motil K, NASPGHAN Committee on Nutrition. Nutrition support for neurologically impaired children: a clinical report on the North American Society for Pediatric Gastroenterology, Hepatology, and Nutrition. JPGN. 2006;43:123-135.

7.) Mehta NM, Compher C, et al. A.S.P.E.N. Clinical Guidelines: Nutrition Support of the Critically Ill child. JPEN. June 2009; 33(3); 260-276.

8.) Mehta N, Bechard L, Dolan M et al. Energy imbalance and the risk of overfeeding in critically ill children. Pediatr Crit Care Med. 2011;12(4): 1-8.

9.) Letton R, Chwals W, Jamie A, Charles B. Early postoperative alterations in infant energy use increases the risk of overfeeding. J Pediatr Surg. 1995. 30:988-993. 10.) Chwals WJ: Overfeeding the critically ill child: Fact or Fantasy? New Horiz 1994;2:147-155.

11.) Adelson $\mathrm{P}$, Bratton $\mathrm{S}$, Carney $\mathrm{N}$, et al. Guidelines for the acute medical management of severe traumatic brain injury in infants, children, and adolescents. Pediatr Crit Care Med. 2003; 4(suppl 3):S72-75.

12.) Brown JE. Nutrtion through the life cycle. $3^{\text {rd }}$ ed. California: Wadsworth Cengage Learning; Chapter 8, Infant nutrition; p.219-245. 


\begin{tabular}{|lc|}
\hline \multicolumn{1}{|c|}{ Diagnoses } & $\boldsymbol{n}$ \\
\hline Brain Anomalies & 6 \\
\hline Cerebral Palsy & 5 \\
\hline Spinal Muscular Atrophy & 3 \\
\hline Neonatal Encephalopathy & 6 \\
\hline Seizures that led to brain damage & 3 \\
\hline Zellwegger's Syndrome & 1 \\
\hline
\end{tabular}

Table 4: Diagnoses included in data analysis 


\begin{tabular}{|lllll|}
\hline & Minimum & Maximum & \multicolumn{1}{c|}{ Mean } & \multicolumn{1}{c|}{$\begin{array}{c}\text { Std. } \\
\text { Deviation }\end{array}$} \\
\hline $\begin{array}{l}\text { Age upon } \\
\text { Admission(months) }\end{array}$ & 0 (birth) & 13 & 1.9 & 3.17 \\
\hline $\begin{array}{l}\text { Average kilocalories per } \\
\text { kilogram body weight } \\
\text { provided }\end{array}$ & $43 \mathrm{kcal} / \mathrm{kg}$ & $144 \mathrm{kcal} / \mathrm{kg}$ & $93.38 \mathrm{kcal} / \mathrm{kg}$ & $34.94 \mathrm{kcal} / \mathrm{kg}$ \\
\hline $\begin{array}{l}\text { Average grams protein } \\
\text { per kilogram bodyweight } \\
\text { provided }\end{array}$ & $.50 \mathrm{~g} / \mathrm{kg}$ & $2.8 \mathrm{~g} / \mathrm{kg}$ & $1.4 \mathrm{~g} / \mathrm{kg}$ & $.69 \mathrm{~g} / \mathrm{kg}$ \\
\hline $\begin{array}{l}\text { Weight for Length } \\
\text { percentile }\end{array}$ & $0-3$ & & & \\
\hline & percentile & percentile & $\begin{array}{l}\text { percentile } \\
\text { percentile }\end{array}$ \\
\hline
\end{tabular}

Table 5: Description of subjects at initial assessment 


\begin{tabular}{|r|r|}
\hline $\begin{array}{r}\text { Group 1 } \\
\mathrm{n}=7\end{array}$ & $\begin{array}{r}\text { Growth patterns highly variable and unpredictable. No trends of patterns } \\
\text { found. Includes patients with limited data. }\end{array}$ \\
\hline Group 2 & Growth patterns response to energy provision predictable; growth similar to \\
$\mathrm{n}=6$ & what would be expected in a healthy infant. \\
\hline Group 3 & Limited to no growth despite adequate energy amounts provided; \\
$\mathrm{n}=6$ & characteristic of hypermetabolism \\
\hline Group 4 & Adequate/extreme growth seen on lower than average kcal/kg amounts; \\
$\mathrm{n}=5$ & characteristic of hypometabolism. \\
\hline
\end{tabular}

Table 6: Description of groups and the growth patterns exhibited 


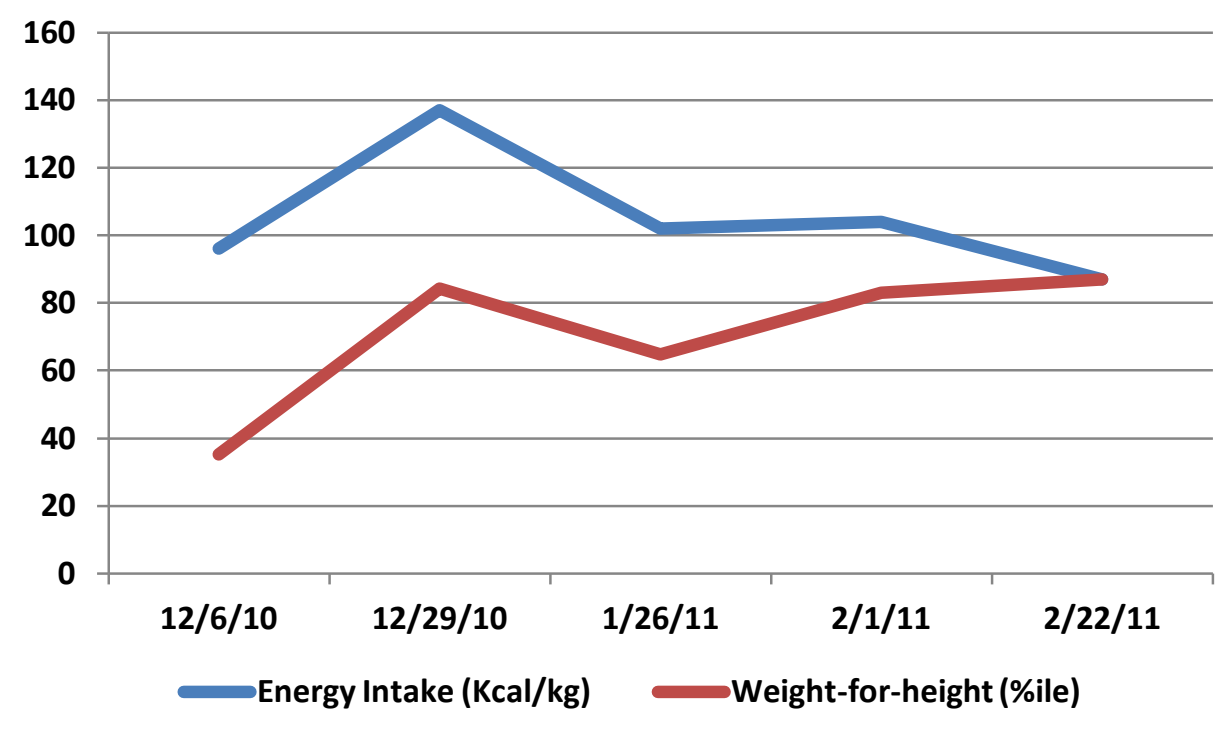

Figure 4: Group $2 \mathrm{Kcal} / \mathrm{kg}$ versus weight for length \% 


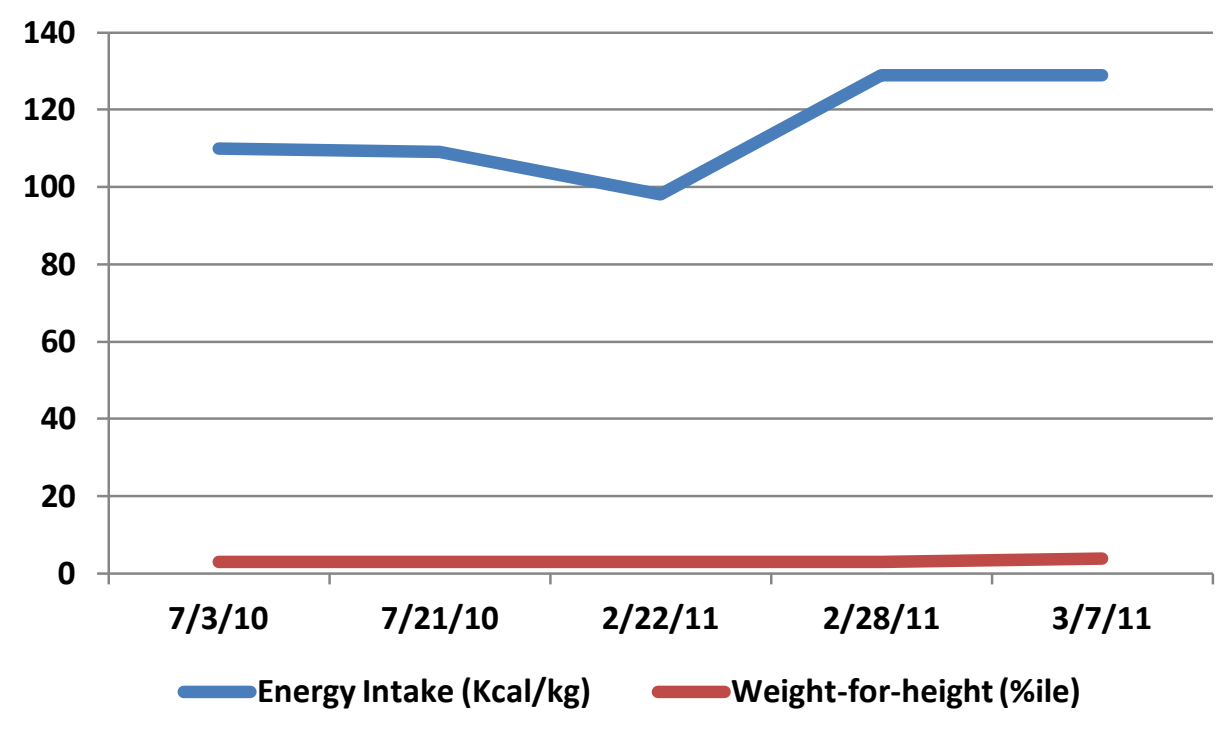

Figure 5: Group $3 \mathrm{Kcal} / \mathrm{kg}$ versus weight for length \% 


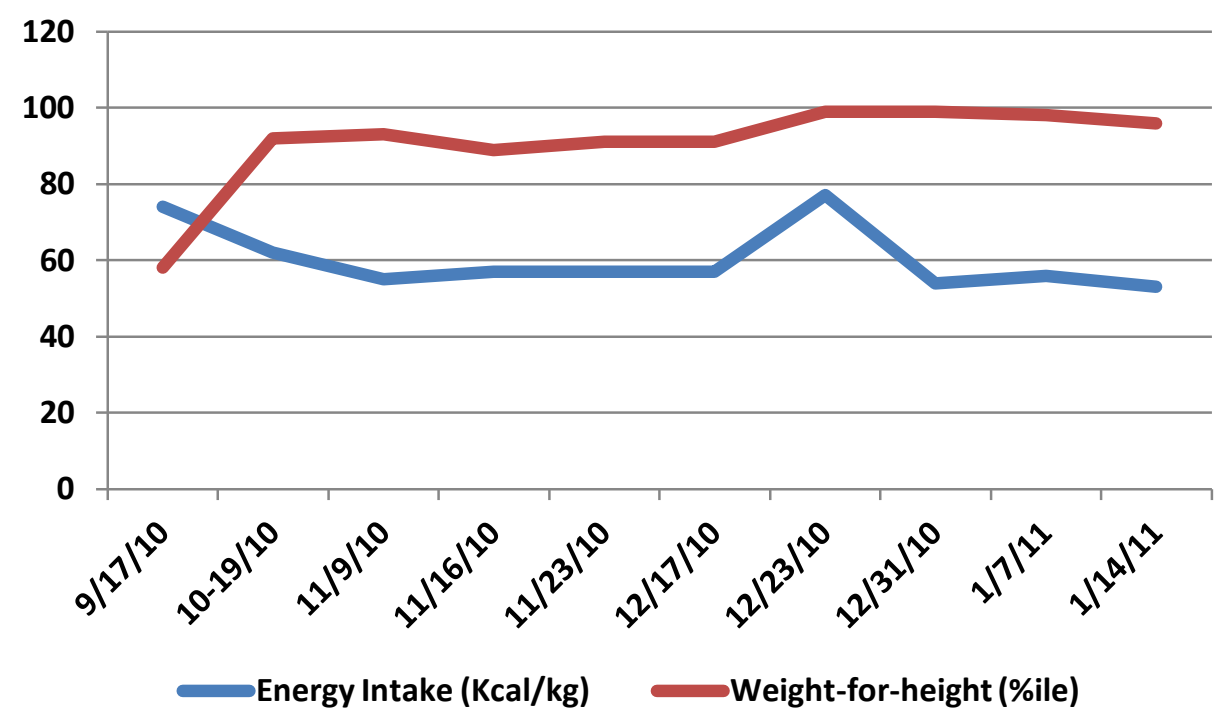

Figure 6: Group $4 \mathrm{Kcal} / \mathrm{kg}$ versus weight for length \% 


\section{References}

1. Byrd-Bredbenner C, Moe G, Beshgetoor D, Berning, J. Perspectives in Nutrition. 8th ed. New York, NY: McGraw-Hill; 2009.

2. Peters A, Schweiger U, Pellerin C, et al. The selfish brain: competition for energy resources. Neurosci Biobehav Rev. April 2004; 28(2):143-180.

3. Nationwide Childrens' Hospital; http://www.nationwidechildrens.org/; November 2010.

4. Lee RD, Nieman DC. Nutritional Assessment. $4^{\text {th }}$ ed. New York: The McGraw-Hill companies; 2007.

5. Caccialanza R, Klersy C, Cereda E, et al. Nutrional parameters assosicated with prolonged hospital stay among ambulatory adult patients. CMAJ. November 2010;182(17):1843-1849.

6. Kyle UG, Coss-Bu JA. Nutritional assessment and length of hospital stay. CMAJ. November 2010; 182(17):1831-1832.

7. Khorasani EN, Mansouri F. Effect of early enteral nutrition on morbidity and mortality in children with burns. Burns. December 2009;36(2010):1067-1071.

8. Nelms M, Sucher K, Long S. Nutrition Therapy and Pathophysiology. Belmont, CA: Thomson Higher Education; 2007.

9. Davis KA, Kinn T, Esposito TJ, et al. Nutritional gain vs. financial gain: The role of metabolic carts in the surgical ICU. J Trauma. 2006; 61: 1436-1440.

10. Mifflin MD, St. Joer ST, Hill LA, et al. A new predictive equation for resting energy expenditure in healthy individuals. Am J Clin Nutr. 1990;51: 241-247.

11. Swinamer D, Grace M, Hamilton S, Jones R, Roberts P, King E. Predictive equation for assessing energy expenditure in mechanically ventilated critically ill patients. Crit Care Med. 1990;18:657-661. 
12. Frankenfield D, Hise M, Malone A, et al. Prediction of Resting Metabolic Rate in Critically Ill Adult Patients: Results of a Systematic Review of the Evidence. J Am Diet Assoc. 2007;107:1552-1561.

13. Brown JE. Nutrtion through the life cycle. $3^{\text {rd }}$ ed. California: Wadsworth Cengage Learning; Chapter 8, Infant nutrition; p.219-245.

14. Agostoni C, Axelson I, Colomb V, et al. The need for nutrition support teams in pediatric units: a commentary by the ESPHAN committee on nutrition. J Pediatr Gastroenterol Nutr. 2005;41:8-11.

15. Tume L, Latten L, Darbyshire A. An evaluation of enteral feeding practices in critically ill children. Nursing in critical care. 2010;291-298.

16. Mehta NM, Compher C, et al. A.S.P.E.N. Clinical Guidelines: Nutrition Support of the Critically Ill child. JPEN. June 2009; 33(3); 260-276.

17. Mahdavi AM, Ostradrahimi A, Sfaiyan A. Subjective global assessment of nutritional status in children. Maternal and Child Nutrition. 2010;6:374-381.

18. McCormick DP, Sarpong K, Jordon L, et al. Infant Obesity: Are we ready to make this Diagnosis. J Pediatr.2010; 157(1):15-19.

19. Shibli R, Rubin L, Akons H, Shaoul R. Morbidity of overweight $\left(>\right.$ or $=85^{\text {th }}$ percentile) in the first two years of life. Pediatrics. 2008;122:267-272.

20. McGuire M, Beerman K. Nutritional Sciences: From Fundamentals to Food. Belmont, CA: Thomson Higher Education; 2007.

21. Wadie G, Lobe T. Gastroesophageal Reflux Disease in Neurologically Impaired Children: The Role of the Gastrostomy Tube. Seminars in Laparoscopic Surgery. 2002; 9(3):180-189.

22. Spinal Muscular Atrophy; Genetics Home Reference, http://ghr.nlm.nih.gov/condition/spinal-muscular-atrophy; October 2011.

23. Wang H, Finkel R, Bertini E, et al. Consensus Statement for Standard of Care in Spinal Muscular Atrophy. J Child Neurol. 2007;22(8); 1027-1049.

24. Department of Rehabilitation Medicine. The epidemiology of Cerebral Palsy: incidence, impairments, and risk factors. Erasmus MC- University Medical Center Rotterdam. 
25. Cerebral palsy; PubMed Health; http://www.ncbi.nlm.nih.gov/pubmedhealth/PMH0001734/; September 2009. June 2011.

26. Kurinczuk J, White-Koning M, Badawi N. Epidemiology of neonatal encephalopathy and hypoxic-ischaemic encephalopathy. Early Hum Dev. 2010; 86(6); 329-338.

27. Birth Asphyxia; Seattle Children's Hospital Research Foundation; http://www.seattlechildrens.org/medical-conditions/airway/birth-asphyxia/;June 2011.

28. Tan S, Wu Y. Etiology and pathogenesis of neonatal encephalopathy; Up to date; http://www.uptodate.com/contents/etiology-and-pathogenesis-of-neonatalencephalopathy; 2011.

29. Battin M. Neonatal Encephalopathy; Newborn Services Clinical Guideline; http://www.adhb.govt.nz/newborn/guidelines/neurology/NE.htm; November 2004.

30. National Institutes of Neurological disorders and stroke; NINDS Zellwegger's Syndrome Information; National Institutes of Health; http://www.ninds.nih.gov/disorders/zellweger/zellweger.htm.

31. Peroxisomal disorders; Medscape reference; drugs, diseases, and procedures. http://emedicine.medscape.com/article/1177387-overview\#a0199.

32. Stanley, A. Withholding artificially provided nutrition and hydration from disabled children-assessing their quality of life. Clin Pediatr. 2000; 39:575-579.

33. Geppert C, Andrews M, Druyan ME. Ethical issues in artificial nutrition and hydration: a review. J Parenter Enteral Nutr.2010;34:79-88.

34. Craig,G. On withholding artificial hydration and nutrition from terminally ill sedated patients; the debate continues. J Med Ethics.1996;22:147-153

35. Frolich T, Richter M, Carbon B et al. Review article:percutaneous endoscopic gastrostomy in infants and children. Aliment Pharmacol Ther. 2010; 31:788-801.

36. Marchand V, Motil K, NASPGHAN Committee on Nutrition. Nutrition support for neurologically impaired children: a clinical report on the North American Society for Pediatric Gastroenterology, Hepatology, and Nutrition. JPGN. 2006;43:123-135.

37. Bandini L, Puelzl-Quinn H, Morelli J, Fukagawa N. Estimate of energy requirements in persons with severe central nervous system impairment. J Pediatr. 1995;126:828832. 
38. Stallings V, Zemel B, Davies J, Cronk C, Charney E. Energy Expenditure of children and adolescents with severe disabilities: a cerebral palsy model. Am J Clin Nutr. 1996;64:627-634.

39. Azcue M, Zello G, Levy L, Pencharz P. Energy expenditure and body composition in children with spastic quadriplegic cerebral palsy. J Pediatr. 1996;129:870-876.

40. Lee $\mathrm{S}$, Cheung $\mathrm{K}$, Ko $\mathrm{C}$, Chiu $\mathrm{H}$. Is there an accurate method to measure metabolic requirement of institutionalized children with spastic cerebral palsy? J Parenter Enteral Nutr. 2011;35:530-534.

41. Mehta N, Bechard L, Dolan M et al. Energy imbalance and the risk of overeeding in critically ill children. Pediatr Crit Care Med. 2011;12(4): 1-8.

42. Letton R, Chwals W, Jamie A, Charles B. Early postoperative alterations in infant energy use increases the risk of overfeeding. J Pediatr Surg. 1995. 30:988-993.

43. 43.Chwals WJ: Overfeeding the critically ill child: Fact or Fantasy? New Horiz 1994;2:147-155.

44. Mascarenhas M, Meyers R, Konek S. Outpatient nutrition management of the neurologically impaired child. Nutr Clin Pract. 2008;23:597-607.

45. Adelson P, Bratton S, Carney N, et al. Guidelines for the acute medical management of severe traumatic brain injury in infants, children, and adolescents. Pediatr Crit Care Med. 2003; 4(suppl 3):S72-75. 


\section{Appendix A}

\section{Data Collection Chart}

\begin{tabular}{|c|c|c|c|c|c|c|}
\hline MR\# & $\begin{array}{l}\text { Date of } \\
\text { Birth: }\end{array}$ & Sex: & Diagnosis: & Status: & $\begin{array}{l}\text { Date of } \\
\text { Enteral } \\
\text { feeding } \\
\text { Initiation: }\end{array}$ & $\begin{array}{l}\mathrm{Wt}: \mathrm{Ht} \% \\
\text { at date of } \\
\text { initiation: }\end{array}$ \\
\hline Date & & & & & & \\
\hline Weight & & & & & & \\
\hline Height & & & & & & \\
\hline $\begin{array}{l}\text { Current } \mathrm{I} \\
\text { Prescripti }\end{array}$ & & & & & & \\
\hline $\mathrm{Kcal} / \mathrm{kg}$ & & & & & & \\
\hline EER & & & & & & \\
\hline EPR & & & & & & \\
\hline $\begin{array}{l}\text { Nutrition } \\
\text { Recomm } \\
\text { from RD }\end{array}$ & & & & & & \\
\hline Kcal/kg & & & & & & \\
\hline $\mathrm{Wt}: \mathrm{Ht} \%$ & & & & & & \\
\hline
\end{tabular}

